\title{
A review of force reduction methods in precision forging axisymmetric shapes
}

\author{
Denis J. Politis ${ }^{1} \cdot$ Nicholas J. Politis ${ }^{1} \cdot$ Jianguo Lin $^{1} \cdot$ Trevor A. Dean $^{2}$
}

Received: 26 January 2018 / Accepted: 7 May 2018 / Published online: 21 May 2018

(C) The Author(s) 2018

\begin{abstract}
This paper provides a review of the methods developed over the years for reducing working forces for the precision metal forming processes. Precision forging normally involves completely, or near completely closed cavity dies with no or minimal draft, making features on the extremities difficult to fill and requiring high loads. Means to minimise load, in order to enhance tool life, or reduce press capacity are crucial to the success of precision forging processes. The main concentration of this study is on design features which can be incorporated in tooling and/or workpiece in order to assist in minimisation of forging load while achieving complete die filling. The load reduction methods are presented using examples mainly of precision gear forging, which is representative of the precision forging of other axisymmetric components with complex peripheral shape. The methods reviewed are divided into the categories of (i) billet design, (ii) tool design and (iii) process design. Their effects on forging load reduction for precision forging, along with the authors' opinions as to the benefits, drawbacks and applicability of each, are presented.
\end{abstract}

Keywords Precision forging $\cdot$ Net shape forging $\cdot$ Gears forging $\cdot$ Forming load reduction $\cdot$ Billet design $\cdot$ Tool design $\cdot$ Forging process design

\section{Introduction}

Precision mechanical components, such as gears, can be produced from a variety of processes depending on the material used. Common processes for manufacturing metallic gears are machining, casting, extrusion and forging. Machining produces accurate gear profiles with the disadvantage of having a comparably low rate of production. It is, however, the most common finishing process for mass-produced precision gears. Casting can be used to manufacture gears that are too large to be produced by other processes, such as those found in ships, agricultural and lifting equipment. The main disadvantage with casting is that the range of high-strength castable alloys is limited and voids can arise in a completed gear thus resulting in 'reduced mechanical properties like brittleness

Denis J. Politis

denis.politis06@imperial.ac.uk

1 Department of Mechanical Engineering, Imperial College London, Exhibition Road, London SW7 2AZ, UK

2 School of Mechanical Engineering, University of Birmingham, Edgbaston, Birmingham B15 2TT, UK and poor surface quality' [1]. An extrusion forging method of manufacturing helical and spur gears has been proposed in the past $[2,3]$. Extrusion forging, usually cold, is used to produce gears having a relatively high tooth width to diameter ratio and often when gears have an axial extension, such as starter motor pinions. An attractive property of extrusionforged components is that the automation of mechanical presses can lead to high productivity, with substantially lower time-per-part than machining. Extrusion forging of narrow, large diameter gears leads to low yield, due to the need for extensive machining on the two end faces which are significantly deformed. Gear forging is essentially an upsetting process, which is particularly effective for gears of a narrow width relative to diameter, compared with extrusion forging [4]. Commercial gears are almost exclusively manufactured from steel, and unless otherwise stated, the following discussion refers to steel gears.

Forging is a particularly attractive manufacturing process, as it offers many advantages over machining and casting, such as high production rate [4], higher utilisation of raw material (30\% increase compared with machining gears [5, 6], for example), reduced cost per part [7,8] and reduced energy for manufacturing $[8,9]$. Perhaps more importantly, the literature 
is in agreement that forging provides added dynamic strength [10] to a gear as opposed to cutting the gear from a solid billet of material, because grain flow aligns in a favourable orientation [11]. Moreover, precision forging (especially at a low temperature) results in excellent surface finish and dimensional accuracy [10, 12]. Miller [13] showed that forged gears exhibit superior performance to machined gears with experimental forgings from the same alloy possessing a fatigue strength as much as seven times higher. Other advantages are that precision forging in some circumstances 'allows the manufacture of gear parts without flash and sometimes without the need for subsequent machining operations' [8]. Moreover, the benefits of near-net/net shape forming of components have been demonstrated by Moriguchi [14], who states that the net shape forming of components 'can eliminate more than half of the total machining necessary to produce any particular part'. Even though this may be an optimistic estimate, the level of material savings due to precision forging is evident from many practical applications. These benefits have encouraged increased use of near-net/net shape or precision forging for production of gears.

Precision forging implies the use of a completely closed die cavity (in comparison with the provision for flash in a closed die cavity for conventional hot forging) and the use of a mechanical or hydraulic press, although in principle, a finely controlled hammer, or screw press, could be used. For manufacture on a single acting press, a sketch of the simplest practical completely closed die forging tool is shown in Fig. 1a. It consists of a punch, counterpunch and die [15]. The die is fixed to the machine bed and the counterpunch, which rests on the machine bed acts as an ejector to remove the completed gear [16]. The tooth shaped punch, which can penetrate the die [15], moves downwards in the vertical direction to reduce the volume of the cavity, thus upsetting a cylindrical billet and forcing it radially into the teeth $[17,18]$.

A typical load/displacement relation for the production of a gear using the closed die forging process is shown in Fig. $1 \mathrm{~b}$. According to $[8,19]$, forging deformation can be described as two main stages: (i) free upsetting - in which the height of the metal decreases and the cross sectional area increases without sideways restraint - and (ii) filling of tooth cavities - where, on further height reduction, the workpiece is extruded into the tooth cavities. However, as seen from Fig. 1b, a major disadvantage of the forging occurs towards the end of the process, where a large load spike is experienced as top and bottom cavity corners (side faces of the teeth) are filled. According to the literature [19], forging becomes particularly difficult with large module gears. Although the length to width ratio of the teeth is independent of module, 'the tooth depth of large module gears is longer which enlarges the radial distance the metal has to extrude and die filling becomes more difficult'. Furthermore, for cold forging, the difficulty of tooth filling is compounded by strain hardening which occurs during plastic deformation and further increases the load as the material begins to fill the tooth cavity [20]. The total frictional force encountered by the workpiece is proportional to contact pressure and contact area, both of which increase throughout the process, hence contributing to the load required for further deformation.

Moreover, towards the final stage of tooth filling, as shown in Fig. 1b, the sharp rise in load at the end of the stroke is explained by Ohga and Kondo [21, 22] as follows: during forging, the unfilled die space in top and bottom corners reduces towards zero. Assuming a completely closed die cavity, as the corners fill, the height of the regions of the billet moving radially tends to zero and the load to infinity. In practical applications, where there is a finite clearance between tool pieces (punch/die and counterpunch/die), either by design or by die expansion due to internal pressure, the load will reach a high, but finite value, due to the formation of flash. Nevertheless, without diversions for metal flow, as discussed below, corners are difficult to fill without employing very high loads, an example of which is shown in the insert of Fig. 1b. Experimental studies on cylindrical components have found that towards the final stage, a ' $1.2 \%$ of the billet deformation (total punch stroke), to fill the corner was accompanied by a load increase of nearly 50\%' [23, 24], which demonstrates the sharp increase in forging load necessary to complete die filling.

Therefore, as a theoretically infinite load is required to fully forge a gear with sharp cornered teeth in a simple closed die, in practice, either the tools would be stressed to failure or the press capacity will be exceeded before complete filling of the die occurs. The sharp increase in load, and the inability of the press and tooling to deliver and withstand theoretically infinite loads, presents a number of problems in the commercial forging of components: (i) high localised die stress causing wear and fracture or plastic deformation [7] and (ii) incomplete corner filling of the die cavity $[19,25]$. The resulting shortened tool life leads to higher per-component cost and increased downtime. It is essential in the net shape and precision forming of gears that complete die filling is achieved [4, $15]$ in order to make precision forging a viable process. A reduction in the forging load required for full filling would improve the tool life and reduce the tonnage of the forging press required, thus reducing the overall cost of forging $[25$, 26]. Therefore, for practical application, forging load reduction is imperative.

Forging load is heavily influenced by the flow stress of the alloy used for the workpiece [27]; composition, temperature, as well as microstructural effects such as grain size and precipitates particularly affect flow stress. Alloys with relatively low yield strength can fill the majority of the die with lower loads than a material with higher yield. For example, aluminium alloys generally require lower forging loads than steels for a given shape. The flow stress of a particular alloy is primarily 
Fig. 1 Precision gear forging (a) set-up and (b) forming force, which increase sharply at the last stage of the forging process. a A gear forging set-up [15, 47]. b Load vs. displacement for closed die gear forging [8]

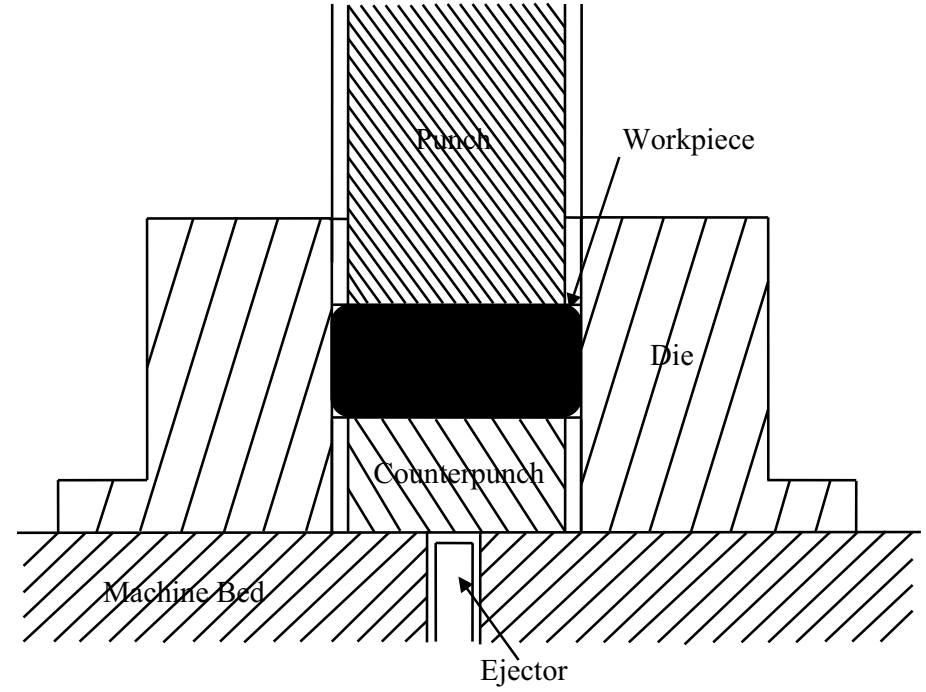

(a) A gear forging setup [15, 47]

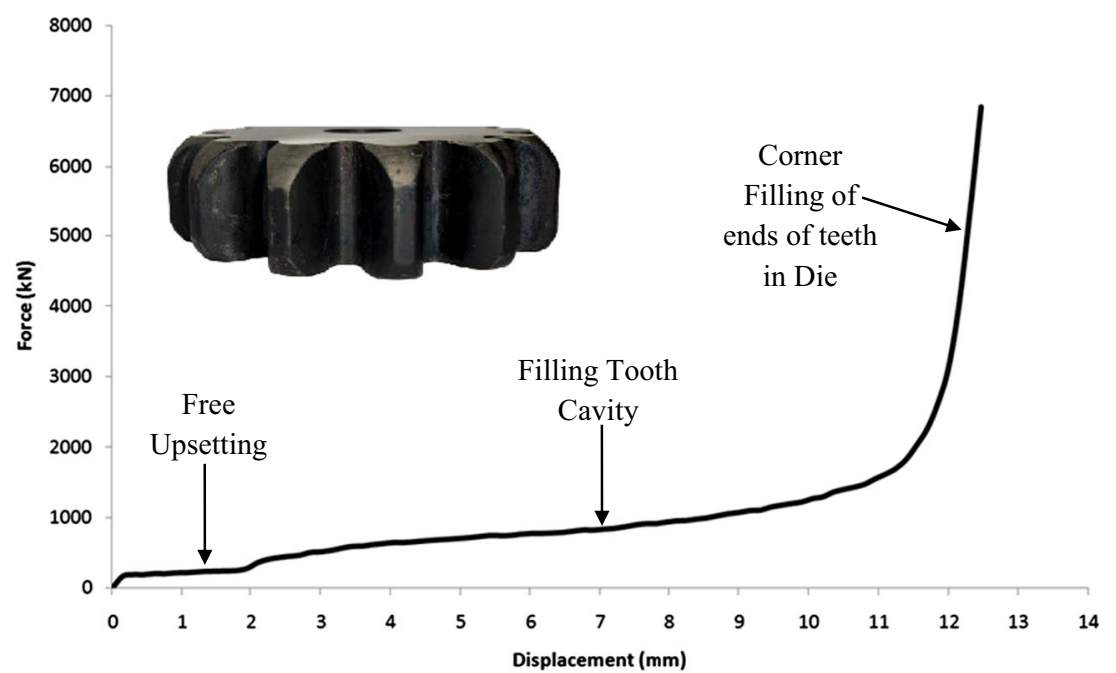

(b) Load vs Displacement for closed die gear forging [8]

which are at a lower temperature is an important factor influencing the forging load [30,31]. The heat transfer characteristics of a forging (and thus billet temperature distribution throughout the forging) are highly dependent on the following: (i) initial workpiece geometry, (ii) final part geometry, (iii) workpiece material, (iv) die material and heat capacity, (v) initial temperature (and temperature distribution if nonuniform) of workpiece and tooling and (vi) interfacial heat transfer properties influenced by roughness, pressure history and lubrication. As temperature effects on forging load are complex and are essentially a materials science related subject, it is not included in this article.

Both shape complexity of a die cavity and preform design influence forging load. Near-net shape forgings often require tight radii and narrow features to be filled, necessitating particularly high forging loads. For simple example, forging a gear with teeth requires higher loads than forging the same cylindrical enclosing geometry. Friction between workpiece
As workpiece temperature is a critical factor influencing the flow stress, heat transfer from the hot workpiece to tools 
and tool has a substantial influence on forging load [30, 32], with an increase in forging load proportional to both an increase in friction coefficient and total contact area. Typically, to reduce forging load, lubrication is applied to tool and or workpiece surfaces. However, the study of lubrication is a vast and complex interdisciplinary topic [33] which, to explain, needs an extensive self-contained treatise and hence it is not dealt with in this article.

This paper, through a review of the literature, presents a guide for engineers to reduce forging loads and achieve die cavity filling exclusively through tool, workpiece and process design methods.

\section{Workpiece geometry}

This section describes the various methods in which the design of the workpiece can be altered in order to reduce the forming force and enhance die filling.

\subsection{Preform shape optimisation}

A fundamental procedure in forging is the selection of the shape of the initial billet (or preform) to achieve various objectives, such as facilitating die filling, increasing yield, reducing forging load and energy and producing desirable flow patterns to eliminate forging defects. For the majority of axisymmetric shapes that are hollow, in comparison with the traditional hot forging method of piercing a shape when it has been formed, using a pre-pierced workpiece in a finishing tool that has a mandrel, by reducing the plan area, will result in reduced forging load.

Historically, optimisation of preform shape has been implemented via trial and error tests in practical applications [34], which is inherently costly and time consuming and does not lead to a design that, with confidence, can be considered optimum (i.e. full 'die filling and fault free, with minimum level of force and waste material.' [35]). Work conducted recently has focused on developing computational algorithms which suggest an optimum preform design, based on an initial predefined forged geometry, without resorting to a trial and error [35-41]. Most optimisation techniques described in the literature depend on an initial geometry defined by the user; hence, the final 'optimum' shape will vary with operator choice. As a result, the optimised blank shape does not necessarily guarantee the ultimate optimal shape possible, as the algorithmic optimisation may converge to a local optimum, not the global one. Algorithms which have been used involve statistical techniques such as a loss function (i.e. the Taguchi method), neural networks and sensitivity analysis. Sedighi and Tokmechi [35] have developed a two-part algorithm, consisting of preliminary preform selection by the user, followed by improvement of the preform geometry. Using finite element (FE) models, the authors have shown that 'by reducing a control criterion $\mathrm{C}_{\mathrm{N}}$ ', which is based on the reduction of simulated load-stroke curves, the preform shape can be optimised, as demonstrated by reducing both forging load and material waste. In their study, the maximum forging load was reduced by $6.8 \%$, during the optimisation process with the amount of flash being nearly halved.

Other proposed preform optimisation methods, such as that by Han et al. [36], use finite element simulation in an attempt to determine the optimal intermediate geometry in a multi-stage forging process by a backward node tracing method. Zhao et al. [37] developed a sensitivity analysis based optimisation, for designing optimal preforms for a variety of forged shapes, by measuring the sensitivity of design criteria (i.e. billet height and width) on the final shape of the forging to achieve even die filling. A preform optimisation method proposed by Lee et al. [37] involved an allegory between flow lines in a forging and equi-potential lines in an electric field to determine the preform shape for an axisymmetric forging. A neural network was used to determine the optimum value of the equi-potential line between the initial and final forged shapes in order to converge to a preform design. Zhao et al. [39] utilised a shape complexity factor, as proposed by Teterin et al. [40] in order to optimise the billet shape by minimising the level of forging difficulty. For a forged component in the shape of a cylinder, the Teterin factor is unity and geometries, requiring material to flow in deep recesses or across tight radii, have greater values of shape complexity factor. By minimising complexity factor for backward deformation in a forging simulation, the authors were able to optimise the billet shape.

Chitkara and Bhutta [41] investigated the effect of changing the workpiece height to diameter ratio of a cylindrical billet (constant diameter, varying height) on the load/stroke curve of the forging of a spur gear. The authors observed that shorter specimens required slightly higher average specimen pressures, although little difference on punch load was observed between specimens. However, results of the study have limited value, due to the variation in workpiece volume which obscured the geometry effect.

It should be noted that preform optimisation studies vary substantially depending on component geometry and hence makes difficult a direct comparison of the effectiveness of each method. An overall comparison could be achieved by standardising component shapes and performing benchmark studies. Optimisation studies mainly investigated load as a tertiary objective, and hence, the utility of optimising the preform purely for the reduction of load is questionable. Also, unless the sequence of cavity filling is radically altered by use of a preform, neglecting changes in mechanical properties during deformation, for closed die forging operations, the same final load will be required for final filling regardless of initial workpiece shape. 


\subsection{Modifying the designed finish forged shape}

Changing the geometry of a forging and hence die cavity by chamfering or rounding top and bottom corners or using large blend radii can reduce the final forging load. This has been demonstrated for the case of cylindrical billet forging [42] with strain hardening alloys. It is common in the forging industry to provide generous fillets on components to take advantage of the effect of reduced load and also to reduce the stress raising effects of sharp corners in die cavities. However, the main disadvantage of this approach is the effect of chamfer/fillet and the amount that can be accepted before significant alterations in appearance and geometry impact the shape specification of a component. Also, the postforging restorative machining that has to be undertaken is costly and reduces yield.

\subsection{Utilising divided flow}

In the case of net or near-net shape forged gear teeth, there is limited flexibility in the use of features, such as blend radii, to reduce forging load as the required geometry could be compromised. Due to the inherent nature of the process, the corners at each end of the teeth tend to be the last to fill. During forging, barrelling occurs where metal flow at the workpiece interface with punch and counterpunch surfaces is retarded (due to friction and/or heat loss) relative to that at the midheight. Thus, the mid-height region of the teeth fill first and ever increasing pressure, depending largely on the value of friction, is necessary to fill teeth ends.

A method proposed by Ohga and Kondo [22], to reduce loads required for filling tooth end corners, is to divide the metal flow so that it simultaneously fills teeth tips and flows, either radially inwards towards the central axis or axially within a central hole. Thus, friction retarding radial flow into the teeth is reduced and the force required to fill teeth is reduced. The two techniques used to promote this divided flow are named: (i) relief hole and (ii) relief axis.

\subsubsection{Relief hole}

For the relief hole (R.H.) principle, a hollow workpiece with bore of radius $r_{i}$ is used, as shown in Fig. 2a (i) [22, 43]. During forging, the material flows both radially outward into the tooth cavities and radially inward thus reducing the diameter of this hole. At any particular stage, the workpiece radius at which material flow transforms from flowing radially inwards to flowing outwards is called the flow divide radius $\left(r_{d}\right)$ [22] and as the direction of friction is reversed at this radius its effect on increasing punch pressure and the overall punch load is reduced. An effect of using a relief hole is that the pressure distribution is more even over the punch/counterpunch contact faces of the workpiece, as the friction hill associated with cylindrical billet compression is reduced in value. This is because in upset forging of a solid cylinder, due to the friction acting on the surfaces of the workpiece, the 'pressure rises monotonically from the edge to the centre' [44]. In addition, a workpiece with central hole has a smaller plan area than a solid cylinder.

For forging using the R.H. principle, a variable which affects the overall load of the forging is the initial diameter of the billet bore. From experimental results conducted by Ohga et al. [21] on a final cavity of dimensions $24 \mathrm{~mm}$ diameter $\times$ $5.4 \mathrm{~mm}$ height, a large relief hole was found to decrease both the overall load and pressure required to fully fill the die from approximately $160 \mathrm{kN}$ for $7 \mathrm{~mm}$ diameter to $100 \mathrm{kN}$ for a $15 \mathrm{~mm}$ diameter hole, as shown by the solid black points in Fig. $2 b$ (i). However, an increased stroke is required to achieve complete die filling as the larger diameter hole requires a taller billet to form the disc to the same final dimensions. Similar results were described by Wei et al. who found that forming load decreased as relief hole diameter increased [25], with results confirmed by Qingping et al. who found the R.H. method filled gear teeth with reduced forging load compared to a solid billet [45].

Furthermore, during R.H. forging, a critical relief hole diameter exists, below which the hole will be fully closed during forging and thus transform the process into solely radially outward flow forging, with concomitant higher load requirement [22]. For the dimensions used in [21], this critical relief hole diameter was approximately $7 \mathrm{~mm}$, where it can be seen from Fig. $2 b$ (i, ii) that the load is substantially higher than for larger relief hole diameters. Thus, in any forging process making use of the R.H. principle, the hole should be carefully dimensioned, taking into account surface friction and workpiece dimensions, to ensure that it does not close during the forging.

The applicability of the relief hole method is limited to components which have a centrally located hole. This precludes its use for solid parts and those having an integral shaft. For such components, the relief axis method, described below, is recommended. It should also be noted that the final relief hole in the finished part will not be necessarily concentric, perfectly circular or the same diameter throughout the height. Machining is required to produce a concentric, circular and cylindrical bore in the gear.

\subsubsection{Relief axis}

The aim of using a relief axis (R.A.) is similar to that of the R.H. principle, to reduce the maximum pressure resulting from the friction hill effect. However, the principle of operation varies from the R.H. principle in that relief holes are located in the punch and counterpunch, on the centre-line of a die cavity [22]. A solid workpiece is used and divided flow is achieved by material flowing both radially outwards into the 


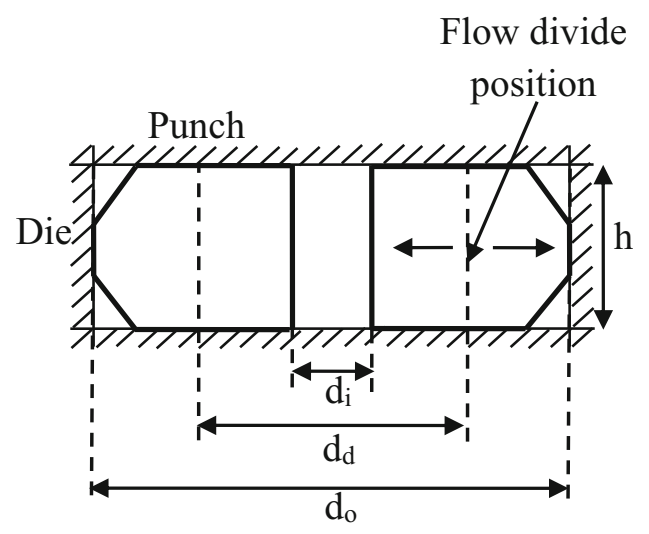

(i) Relief Hole concept

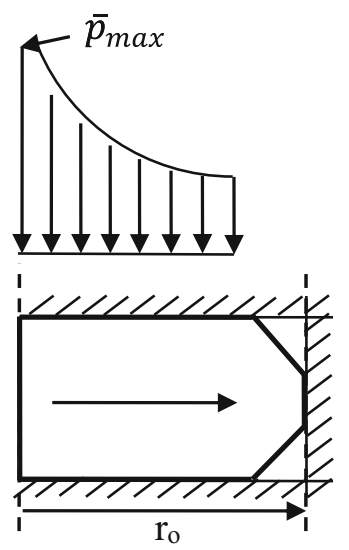

Closed Die

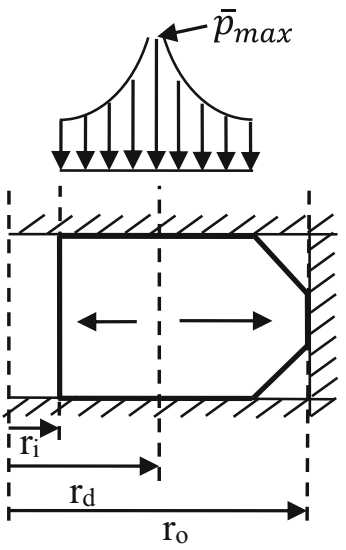

Relief Hole

(ii) Effect on friction hill

(a) Relief Hole Principle [43]

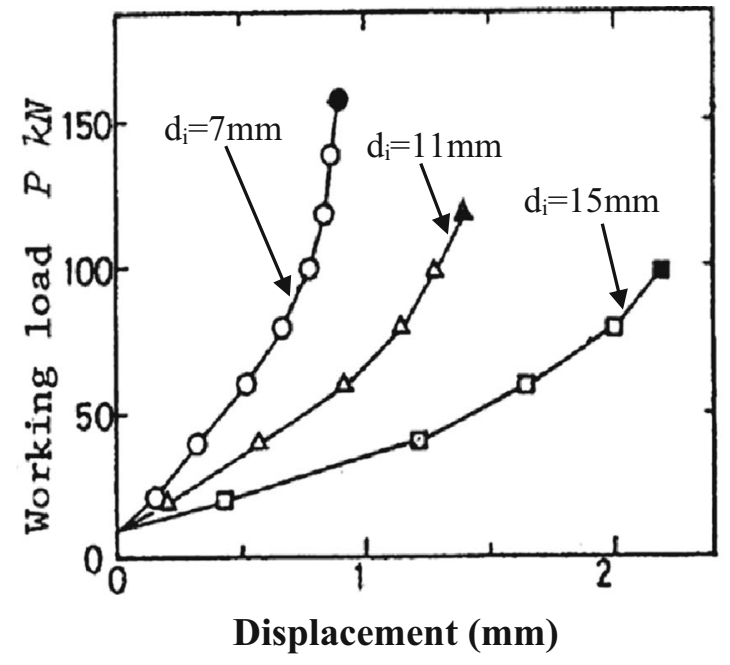

(i) Load-displacement diagram

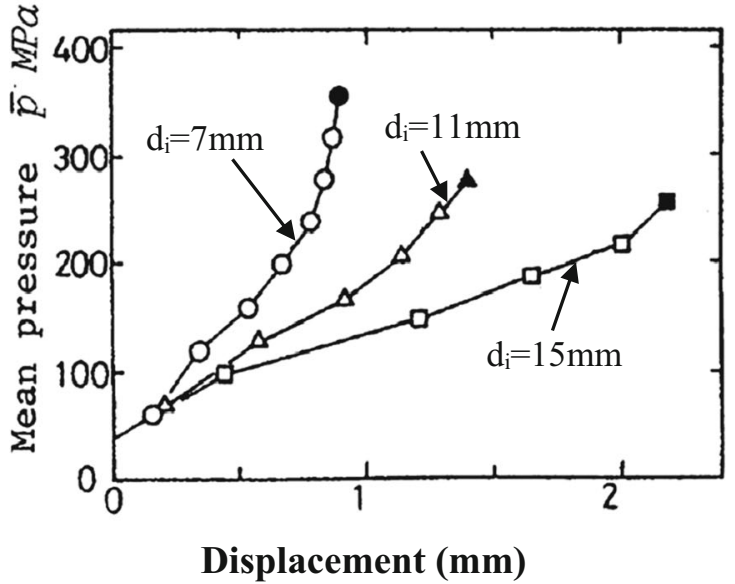

(ii) Pressure-displacement diagram

(b) Effect of Relief Hole diameters [21]

Fig. 2 Creation of a central relief hole (R.H.) in workpiece to enhance material flow (i), which reduces the value of friction hill (ii) (a). This results in reduced working load (i) and mean forming pressure (ii) (b). a Relief hole principle [43]. b Effect of relief hole diameters [21]

teeth and simultaneously radially inwards into the hole (shown in Fig. 3a (i)). Similar to the R.H. principle, this method reduces the maximum pressure due to amelioration of the friction hill effect (Fig. 3a (ii)). Also, full closure of the cavity is avoided and compensation space for material volume variation provided, obviating overloading. The R.A. method can be considered as being based on both tool design and workpiece design as the relief axes are located in the punch and counterpunch.

Figure $3 b(i$, ii) shows the experimental results obtained by Ohga et al. [21] using the R.A. method for forging a disc. As can be seen from the graphs, all three relief axis sizes allow for the full forming of the component (shown by the filled black points). Similar to the R.H. principle, a larger relief axis allows for a reduced overall working load (from approx. $140 \mathrm{kN}$ at $8 \mathrm{~mm}$ diameter to $75 \mathrm{kN}$ at $16 \mathrm{~mm}$ diameter). The consequence of this is that the stroke $S$ is significantly increased, where in the case of this study, the use of a 16- $\mathrm{mm}$ instead of an 8-mm relief axis results in the stroke more than doubling. Taller preforms/ billets are needed to achieve the same final product height and material wastage will be incurred unless an integral shaft is required on the component. In this case, the cylindrical cavities should be longer than the shaft length required, thus ensuring metal can flow along the axis for the duration of tooth filling. 


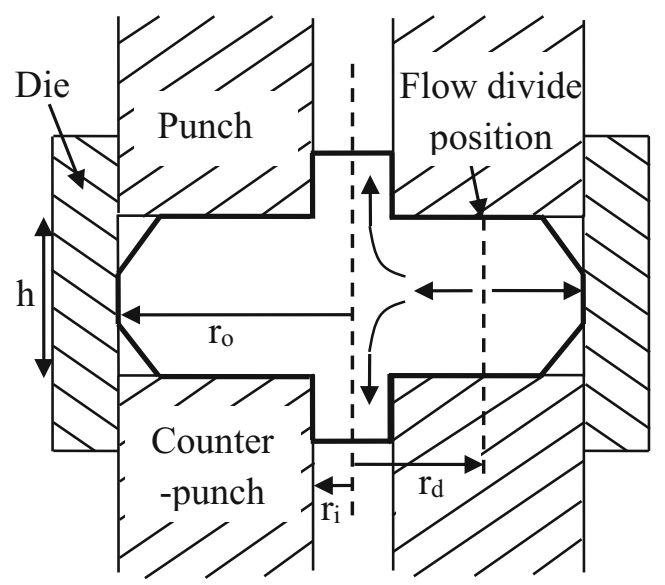

(i) Relief Axis concept

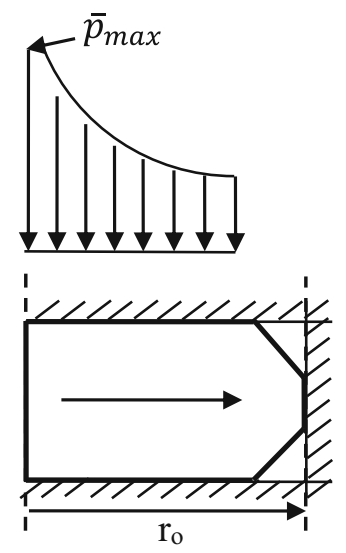

Closed Die

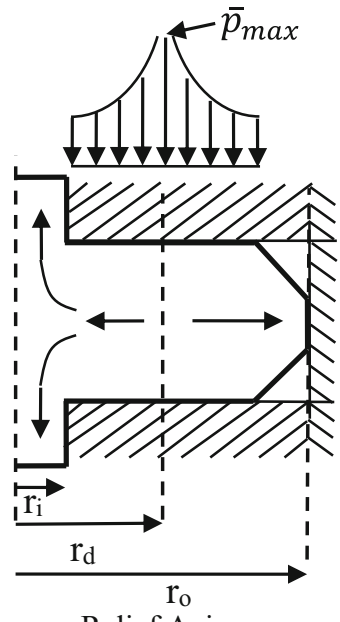

Relief Axis

(ii) Effect on friction hill

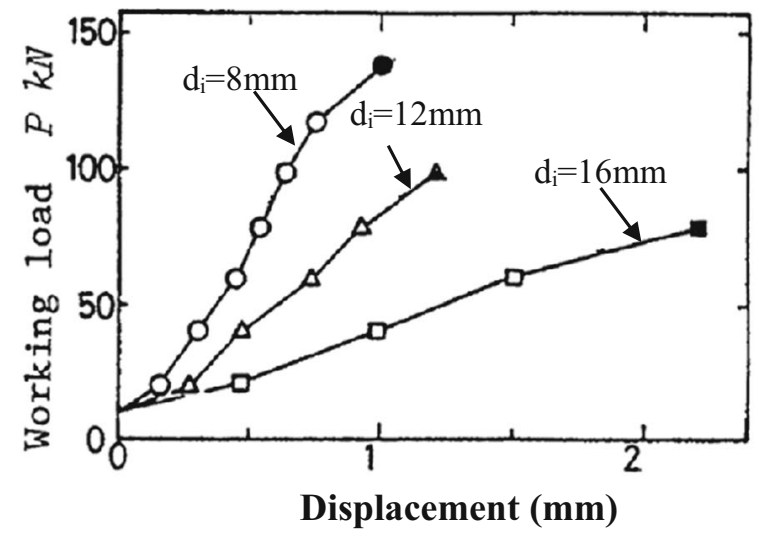

(i) Load-displacement diagram

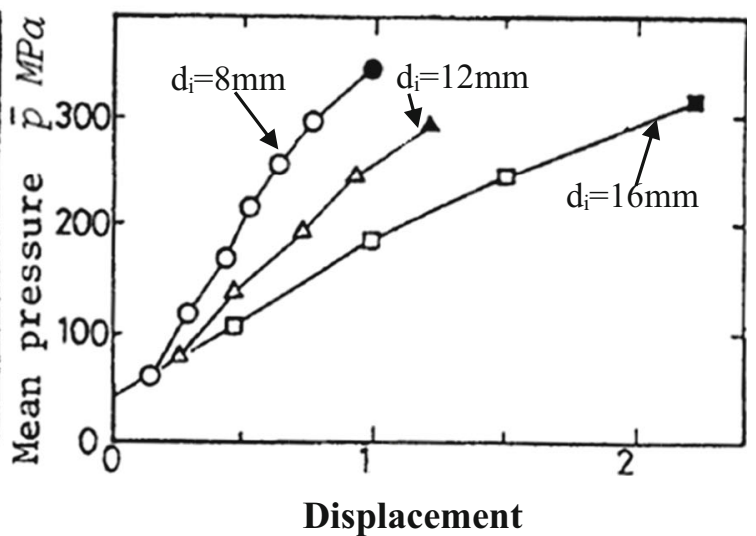

(ii) Pressure-displacement diagram

(b) Effect of Relief Axis diameters [21]

Fig. 3 Creation of central relief axis (R.A.) holes in the die and punch to allow material flow (i), which reduces the value of friction hill (ii) (a). This results in reduced working load (i) and mean forming pressure (ii) (b). a Relief axis principle [22]. b Effect of relief axis diameters [21]

A comparison of the working load and pressure for R.A. and R.H. processes is shown in Fig. 4. As can be seen from Fig. 4a, both R.A. and R.H reduce working load with increasing hole diameter, with R.H. showing a consistently higher load for diameters. Moreover, as can be seen from Fig. 4b, the R.A. principle differs from R.H. in that there exists a minimum mean working pressure of approximately $300 \mathrm{MPa}$ at $12 \mathrm{~mm}$ diameter, above which the mean pressure increases again. However, it should be noted that few data points are presented in the study, and as such, it is difficult to conclude on an absolute minimum value without further experimental work being conducted with hole diameter values around the proposed minimum, for example at 11 and $13 \mathrm{~mm}$. Assuming the presence of a minimal value, according to [22], 'the optimum diameter minimizes working pressure', thus, according to the authors, minimising tool wear. Ohga et al. [21] explain that the decrease in working pressure with increasing diameter for both R.H. and R.A. is due to the fact that the area of specimen in contact with the die reduces, thus reducing the fractional reduction in area, directly reducing the contribution of friction to forging pressure. The authors [21] suggest that, in the R.A. method, increasing the diameter leads to more restricted material flow into the axis, which is due to additional shearing work required for axial flow [21], having the effect of increasing the pressure. This means that 'due to a balance of these two phenomena, there will exist an optimum for minimising working pressure' [21]. However, as there is only one data point to suggest such a phenomenon (at an R.A. 


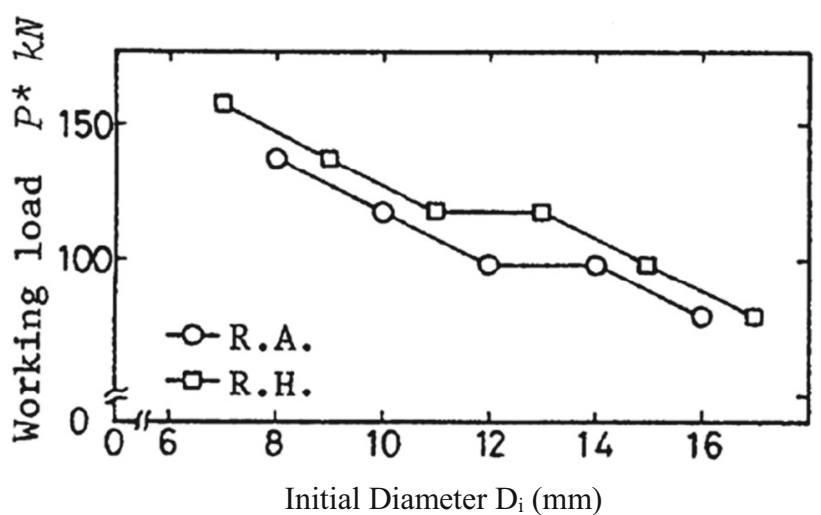

(a) Forging load

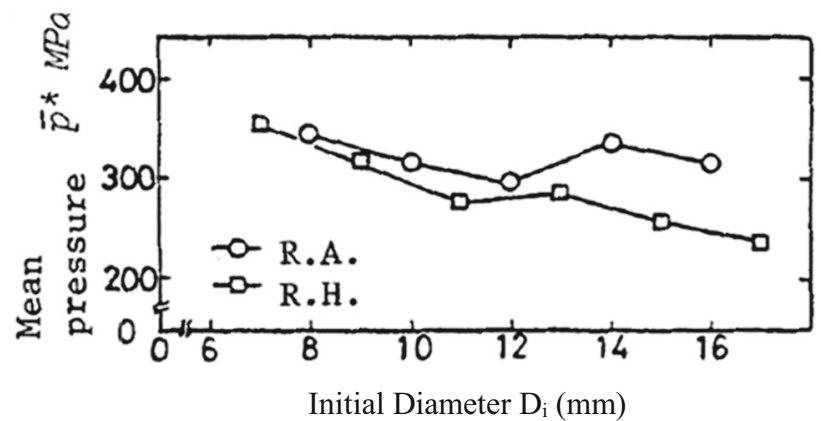

(b) Mean pressure

Fig. 4 Comparison of a working load reduction features and $\mathbf{b}$ mean pressure required for die filling for the two relief methods: relief axis (R.A.) and relief hole (R.H.) [21]. a Forging load. b Mean pressure

diameter of $12 \mathrm{~mm}$, showing a pressure difference of $\sim 16 \%$ from the maximum), this conclusion may require further validation.

Despite the reductions in pressure and load offered by the RA method, it does have disadvantages. Ohga et al. [46] state that the process 'is hard to apply to products with complicated circumference'. This is because such shapes require a much larger degree of radially outward flow for complete die filling. An example of such products is gears, with teeth profile forming a significant flow restriction, thus increasing flow into the relief axis. A further study investigated the effects of a limited depth relief axis on the working load [43] on the forging of a spur gear. The results of the research support the use of a relief axis as an effective method of reducing load. In this case, it was found that as the depth of the relief axis increased, the working load reduced, with reductions of 8 $11 \%$ load from solid forgings.

\section{Tool design}

\subsection{Kinematic arrangements}

As discussed in Section 1, the basic tool set-up for completely closed die forging of a solid shape consists of three components: a punch, counterpunch (or anvil) and die. However, the literature has shown that the kinematic relation between these components has a great effect on required load.

\subsubsection{Three-piece toolset}

According to the literature [15, 47], considering conventional single acting presses, it is possible to position these three components to provide various kinematic combinations. For example, with reference to the die, the punch can be either 'penetrating or non-penetrating', the die can be fixed either to the machine bed, or to the slide, or movable in the vertical direction and, with reference to the die, the counterpunch can be either of non-penetrating or of a penetrating form to act as an ejector. Moreover, the entire tool set can be inverted, i.e. the punch attached to the machine bed and counterpunch attached to the moving ram, thus providing a total of 16 tool set possibilities. However, according to Tuncer and Dean [15], difficulties in ejecting the forged gear result in only six viable combinations. Figure 5 shows examples of these combinations. As can be seen from Fig. 5a, one possibility is to support the die on springs to allow it to move in the vertical direction. The punch is of a non-penetrating form, and the counterpunch is fixed to the machine bed. During forging, the punch first comes into contact with the die, and they both move down at the ram velocity over the stationary counterpunch to forge the gear. Another combination of an inverted tool set is shown in Fig. 5b. The punch is fixed to the machine bed and penetrates the die which is attached, with the counterpunch, to the ram.

\subsubsection{Four-piece toolset}

The addition of a mandrel to a toolset $[15,18]$ enables a hollow workpiece to be forged, in contrast to the solid workpieces used in three-piece toolsets. Use of a hollow workpiece offers the benefits of (i) accurate forging of central bores, which are a typical feature in axisymmetric forged components, which are often attached to shafts, (ii) reduction in forging load due to reduced tool/workpiece contact area and (iii) if a hollow billet is used as raw material rather than being pierced as a first forging operation, faster heating rate, as billet volume is reduced and heating takes place both in the inner and outer surfaces. Therefore, in hollow billet gear forging, there are four main components present in the tool, namely: die, counterpunch, punch and mandrel. According to Tuncer and Dean [18], this brings about 18 different practical kinematic combinations for tool components: (a) 4 possibilities for the punch: hollow, solid, penetrating and non-penetrating; (b) 4 possibilities for the die: attached to the ram, to the machine bed and to have these fixed or movable; (c) 4 combinations of mandrel: attached to the counterpunch or punch as either rigid or movable components; (d) 4 combinations of counterpunch which is either fixed or movable and either solid or hollow 
Fig. 5 Three types of tool set arrangements for load reduction and enhanced die filling. a Moving die [47]. b Fixed die [47]. c Moving die, moving mandrel, non-penetrating punch and penetrating counterpunch [18]

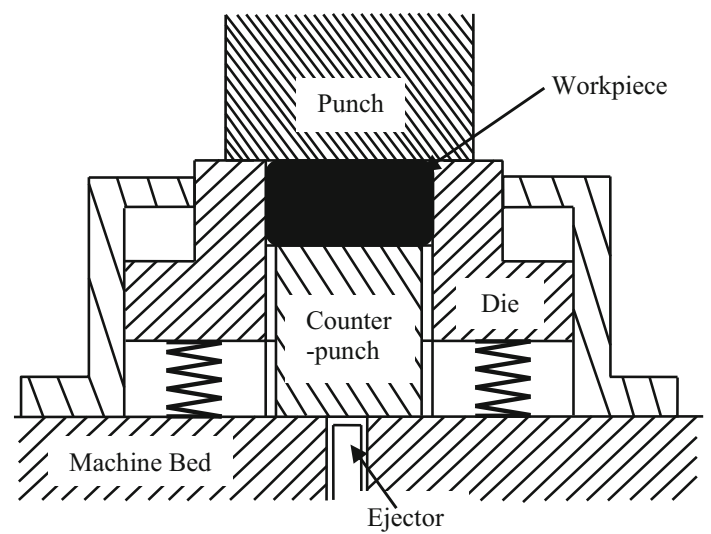

(a) Moving die [47]

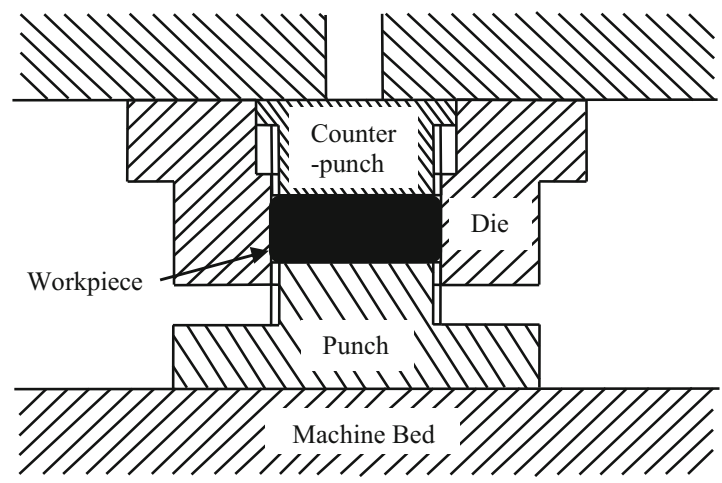

(b) Fixed die [4 7]

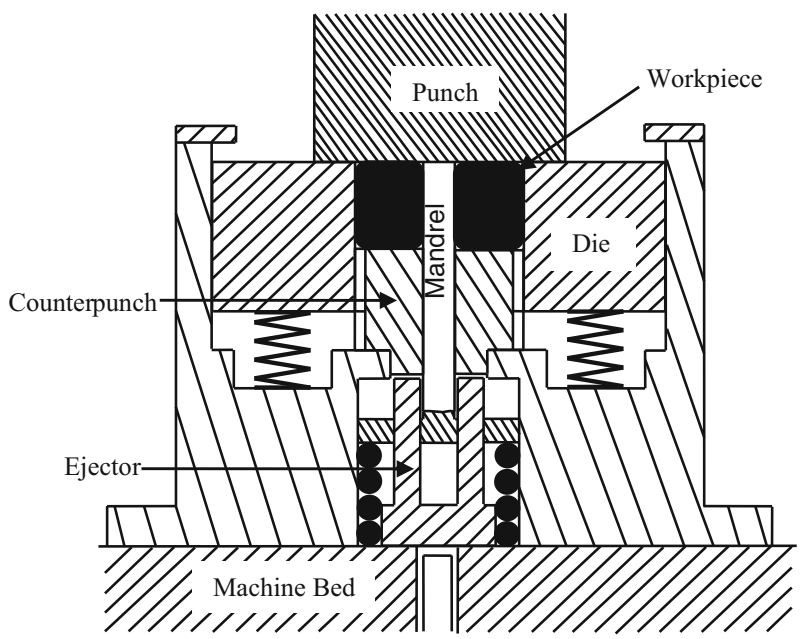

(c) Moving Die, Moving Mandrel, Non-penetrating Punch and Penetrating Counterpunch [18] depending on mandrel arrangement; and (e) 2 combinations of die and mandrel positioning where they are attached to either the moving ram or the stationary machine bed. An example of a movable die and mandrel over a non-penetrating punch and penetrating counterpunch is shown in Fig. 5c.

A punch which is of a non-penetrating form has the advantage of being low cost as accurate matching with the die cavity is not required. Also, its accurate guidance is not critical. A penetrating counterpunch may be used to eject a forged part. According to the literature [23], a sprung die moved by a non-penetrating punch facilitates die filling in the direction of its travel due to directing friction forces on its bore. A floating die (with weight supported on springs), penetrating punch and counterpunch, causes peripheral friction to be opposed about some intermediate workpiece die wall contact region, balancing flow into top and bottom corners of the cavity and facilitating cavity filling. It has been found [23] that the moving die design exhibited a 
$21 \%$ lower load to forge the gear compared to the fixed die design. Therefore, depending on forged shape, a moving die is preferred to assist die filling and reduce forming forces, if difficult to fill features that are situated on the lower regions of a shape. Further details of load reduction with tooling arrangement are described by Tuncer [48].

\subsection{Punch and Counterpunch Design}

Research conducted by Hu et al. [49] investigated the effects of non-flat cross-sectional profiles of the punch and counterpunch in the forging of a 20 tooth, 2.5 module spur gear. The profiles investigated in the paper protrude into the die cavity, with the aim of providing a more uniform deformation throughout the volume of the workpiece compared with flat surfaces that cause barrelling. In the study, the punch had a 'W'-shaped surface as opposed to a flat surface, with the counterpunch surface having an inverted ' $V$ ' or conical shape. In this configuration, the workpiece contacted the peripheral teeth forms along their whole lengths, almost simultaneously, thus enhancing corner filling. The conical form should reduce the value of the component of friction opposing corner filling, but as no load-stroke curves are presented in the paper, whether or not this is so is unknown.

In another study, the effect of various component arrangements in a three-piece toolset when forging bevel gears was investigated (Fig. 6a) [50]. A variation of the toolset involves two punches: an upper and a lower one, which move together in opposite directions to forge the billet (Fig. 6a (ii)). Numerical analysis predicted maximum forming punch load in uni- and bi-directional forging that was 3012 and $2503 \mathrm{kN}$ respectively [50] (Fig. 6b), confirming that bidirectional forging is effective at reducing punch load compared to uni-directional forging. Again one reason for this difference is due to the fact that bi-directional forging is essentially the same as that with a floating die and penetrating punches and promotes a more uniform strain and velocity distribution within the tooth profile, similar to that found in the study by $\mathrm{Hu}$ et al. [49].

\subsection{Axially driven die}

A method proposed by Osakada et al. [51] and Wang et al. [52] to reduce tool pressure in the flashless forging of a spline involved oscillating the die axially via a secondary press system during deformation. It is postulated that by moving the die, the effect of the frictional force can be such that the billet material is forced into the corner of the die, as shown in Fig. $7 \mathrm{a}$, resulting in corner filling with lower punch load [51]. This effect is shown in Fig. 7b, where it can be seen that an oscillating die reduced forging load compared with that necessary when either a fixed or floating die was used.
Further experimental trials conducted by the researchers involved oscillating the die at an amplitude of approximately $2 \mathrm{~mm}$ (for a 16 tooth spline of approximately $25 \mathrm{~mm}$ diameter) and a frequency of $0.1 \mathrm{~Hz}$. The results of punch pressure, calculated by dividing the average pressure of the punch with material flow stress, are shown in Fig. 7b [51], where it is observed that the oscillating die technique can significantly reduce the pressure. A 57\% reduction in punch pressure was recorded when compared to a fixed die arrangement and a $46 \%$ reduction when compared to a floating die [51] for the set-up used. Thus, at the cost of a more complex tooling set-up that is not described in the paper, the oscillating die technique can offer substantial load reductions for parts such as spur gears or splines. The applicability of this method might be limited to forgings with only axially oriented features, unless a practical means for driving dies non-axially are developed.

\subsection{Flow restriction}

The flow restriction method is a variation of the relief hole technique which incorporates the relief hole (radius $r_{i}$ ) in a workpiece and restricts the flow in the radially inward direction. This is performed by reducing the thickness of flow through the use of a central stud (radius $r_{k}$ ) which protrudes by a distance $k$ from punch and counterpunch, as shown in Fig. 8a. According to the literature 'if the inward flow rate is suppressed and the outward one promoted, filling at the outer radius is expected to become more effective' [53].

Ohga et al. [53] proposed that inward material flow can be controlled by selecting the value of $k$ during the stroke. Two methods were investigated, namely type ' $\mathrm{k}$ fixed' and type ' $\mathrm{k}$ free'. The $\mathrm{k}$ fixed method is where the stud protrusion $k$ is held constant throughout the stroke, whereas the type $\mathrm{k}$ free is where the stud is free to move upwards when the workpiece pressure acts on its end face. It is possible that a $\mathrm{k}$ free stud will move upwards behind the punch surface during deformation. The effect would be to produce a situation where both the 'relief-hole principle (R.H.) is combined with the flow reliefaxis one (R.A.)' thus giving it the name 'R.H.-R.A. combined' [53]. As long as $r_{i}>r_{k}$, the method acts as the relief hole principle. However, when $r_{i}=0$ (i.e. the central hole completely closes up), type R.H.-R.A. combined becomes the relief axis method.

The tool pressure with regard to the initial diameter of the relief hole of the workpiece $\left(D_{i}\right)$ is shown in Fig. $8 \mathrm{~b}$ for both the type $\mathrm{k}$ fixed and $\mathrm{k}$ free methods for an initial $k$ value of $k=$ $1.5 \mathrm{~mm}$ and $k=0.5 \mathrm{~mm}$ respectively. For comparison, $h=$ $2.6 \mathrm{~mm}$ and $r_{k}=6 \mathrm{~mm}$. The figure presents the experimental results obtained by [53] at complete die filling.

As can be seen from Fig. 8b, the pressure for type $\mathrm{k}$ free is consistently below that of $\mathrm{k}$ fixed and hence "is preferable for improving the tool life' [53]. As can be seen from Fig. 8b (i, ii), it can be seen that for the $\mathrm{k}$ fixed method, there appears to 
Fig. 6 Comparison of punch design combinations (a) and their effect of forging load (b). a Punch designs [50]. b Load-

displacement diagram for punch designs [50]

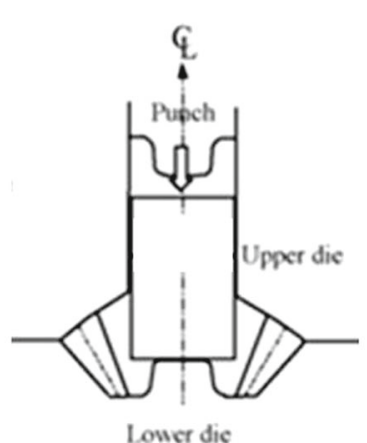

(i) Single Punch

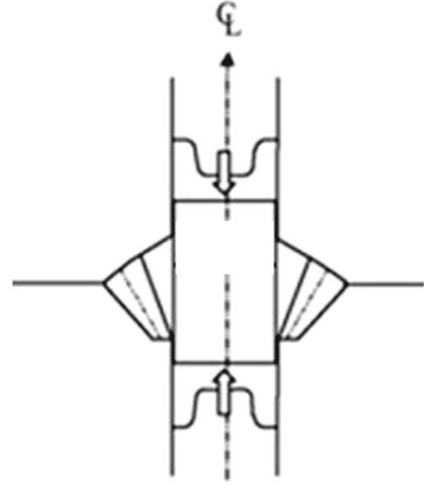

(ii) Dual Punch

(a) Punch Designs [50]

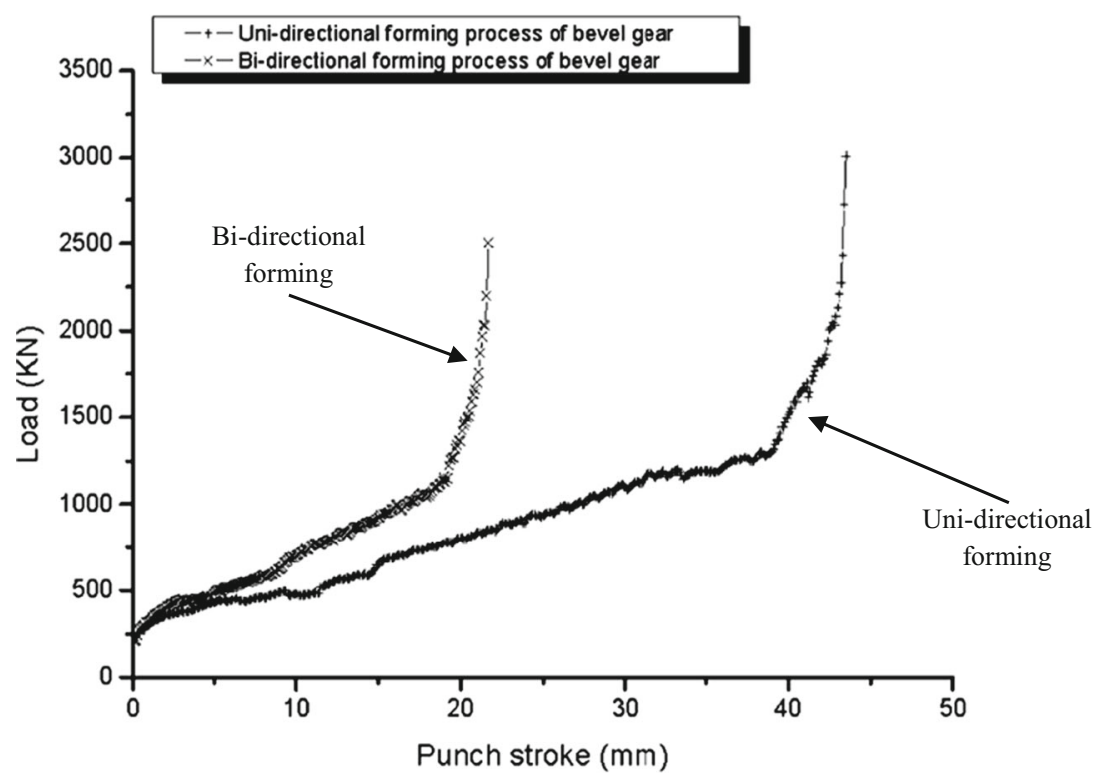

(b) Load-displacement diagram for punch designs [50]

be an optimum value of $k$ for a given relief hole diameter whereby the pressure on the tool is substantially decreased. According to [53], careful selection of these values reduces the pressure 'below that in the process utilizing the reliefhole'. However, it should be noted that there are very few data points to support this conclusion. It is recommended that further studies are performed around the proposed optimal diameter to improve accuracy and confidence in the conclusion.

Along with pressure, the final height of the formed component is affected by the method used. Both forming pressure and final billet height after forging were examined experimentally by Ohga et al. [53]. The results of experiments using initial billet dimensions of $24 \mathrm{~mm}$ outer diameter $\times 5.4 \mathrm{~mm}$ height for the above-mentioned methods are compared with the relief hole and relief axis methods mentioned in Sections 2.3.1 and 2.3.2, and presented in Table 1. In the table, it can be seen that the method which exhibits the largest final height is the most efficient method in the use of material. As shown in Table 1, both relief axis and type $\mathrm{k}$ fixed exhibit the largest final height of $4.2 \mathrm{~mm}$. Furthermore, the method which exhibits the lowest pressure value is the one which applies the least stress on the tool and hence increases tool life. Table 1 shows that the lowest pressure is found in the type $\mathrm{k}$ free method with a value of $210 \mathrm{MPa}$. A comparison of the forming pressure against the final forged height is shown in Fig. 9 where the number of each point corresponds to the methods shown in Table 1.

According to [53], a $45^{\circ}$ line labelled as N-N can be added to the diagram in order to find the most effective compromise between reducing forming pressure and conserving material, assuming that pressure reduction and material conservation are equally significant. Should the relative significance of 


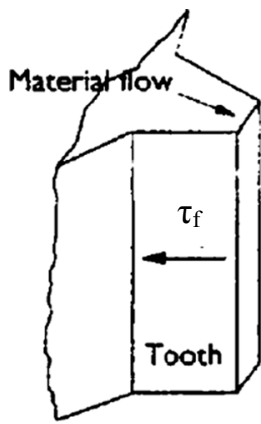

(i) Fixed/floating die

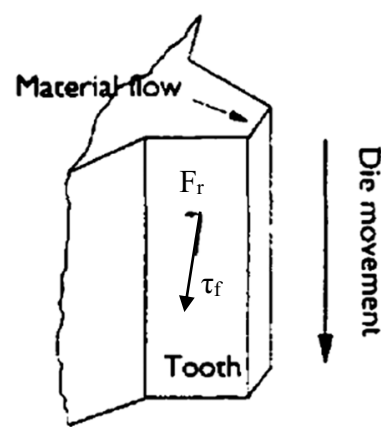

(ii) Axially driven die (a) Frictional effect on die [51]

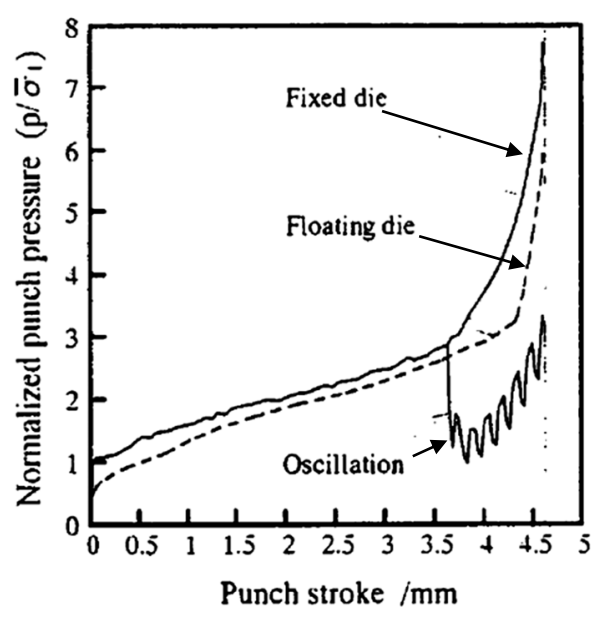

(b) Pressure-displacement diagram for die setup [51]

Fig. 7 Comparison of frictional force effect (a) of fixed/floating die and oscillating die arrangements on forging pressure (b). a Frictional effect on die [51]. b Pressure-displacement diagram for die set-up [51]

forming pressure and billet height be different, various angles of the N-N line can be used, with a shallower gradient indicating that forming pressure is of greater significance than final billet height. The method 'which exists nearest to the line $\mathrm{N}-\mathrm{N}$ is the most effective one', assuming the authors' chosen $45^{\circ}$ line is optimum. Therefore, as can be seen from the figure, for the particular geometry investigated, the rating in order of effectiveness is as follows: (i) type $\mathrm{k}$ free, (ii) type 'R.H.-R.A. combined', (iii) type k fixed, (iv) process R.H. and (v) process R.A. Therefore, it can be concluded that restricting flow in the inward direction does improve the forming process in terms of reducing forming load and material wastage.

\subsection{Chamfered punch/counterpunch}

A punch and/or counterpunch, chamfered at the periphery, is a simple means for reducing maximum forging loads.

As has been explained above, because of the effective height to diameter of the deforming region and the friction hill, a flat punch and counterpunch (Fig. 10a (i)) require large loads to fully fill the outermost tooth corners of large diameter gears. A means for overcoming this problem is to chamfer punch and counterpunch in these regions, as shown in Fig. 10a (ii). The full tooth width can be formed by the workpiece without the need for the enlarged corner space to be filled [54], as shown in Fig. 10b (ii). Thus components of the required dimensions can be produced before a sharp increase in corner filling pressure occurs. The extra material which accumulates in the chamfered corner space can then be removed in a simple post-forging machining process. A comparison of toolsets with and without chamfered punch and counterpunch is shown in Fig. 10a, with the final simulation stages for these toolsets shown in Fig. 10b. It is to be noted that the toolsets in this figure have a nonpenetrating punch and moveable die. This enhances flow into the bottom corners of the die, so the top chamfer is more important for top corner filing.

Simulation results for warm forming a gear of material AISI $8620 \mathrm{H}$ and dimensions: $36 \mathrm{~mm}$ height, module $4.233 \mathrm{~mm}$ and 27 gear teeth [23] are shown in Fig. 10c. Load-displacement results are plotted for both moving and fixed dies, and for chamfered and flat punch and counterpunch. It can be seen that the moving die load is substantially lower $(21 \%)$ than that for the fixed die. Furthermore, it can be seen that the chamfered components require a significantly lower load to forge the same gear compared to flat components. For the fixed die, there is a load reduction of $39 \%$ and for a moving die a load reduction of $48 \%$.

Therefore, it can be seen that a chamfered punch and counterpunch is substantially effective in reducing forging loads. The method is very low cost and easy to implement, only requiring modification of punch and counterpunch. However, the consequence of using the method is that there must be a post-forming machining operation to remove the excess material, which would add time and cost to production.

\section{Process design}

\subsection{Process parameter optimisation}

Computer-based process parameter optimisation has been actively researched in recent years $[55,56]$, dealing with variables, such as temperature and ram speed, in order to minimise the forging load, material loss and tool pressure. Typically, process optimisation procedures deal with the following variables: preform size and shape, intermediate die and finish forge die design [57], billet temperature, lubrication and, if there is a choice of machine, forging speed. FE models in combination with Taguchi statistical loss function methods have been used to optimise such parameters. Chen [58] and Feng and Hua [25] have presented a parameter optimisation method for temperature, punch velocity and friction for the gear hot forging process based upon finite element simulation 
Fig. 8 Concept of flow restriction method (a) and effect on forging pressure (b) for full die filling with the types ' $\mathrm{k}$ fixed' and ' $\mathrm{k}$ free'. a Flow restriction principle [53]. b Pressure profiles for types ' $\mathrm{k}$ fixed' and ' $\mathrm{k}$ free', where $\mathrm{k}=$ mandrel protrusion distance [53]

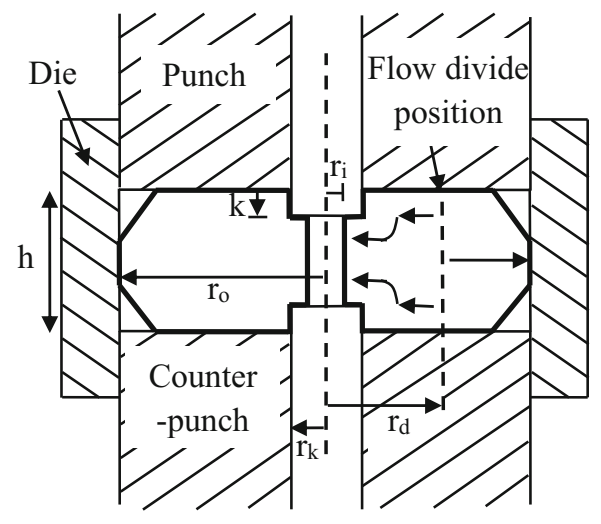

(a) Flow Restriction Principle [53]

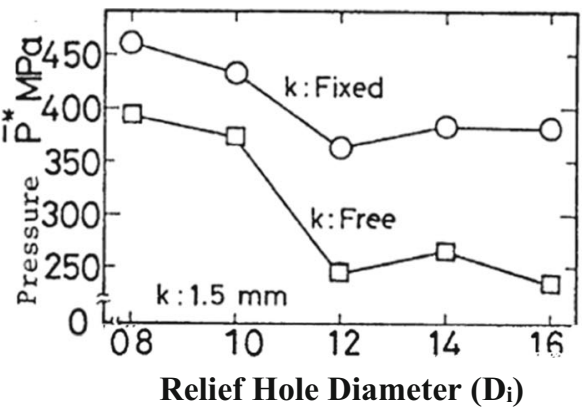

(i) Pressure for $\mathrm{k}=1.5 \mathrm{~mm}$

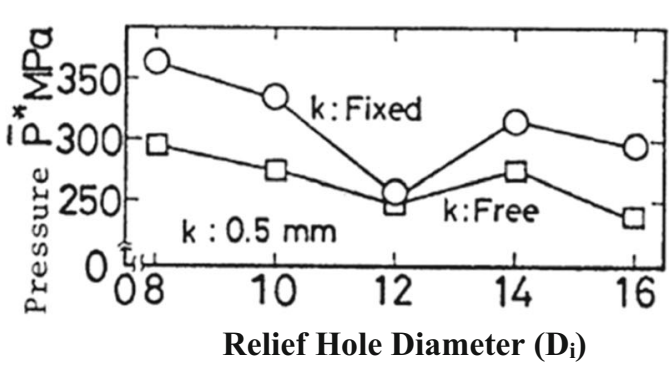

(ii) Pressure for $\mathrm{k}=0.5 \mathrm{~mm}$

(b) Pressure profiles for types ' $k$ fixed' and ' $k$ free', where $k=$ mandrel protrusion distance [53]

and Taguchi statistical analysis [59]. Feng and Hua [25] performed an optimisation, minimising forging force and stroke, for closed die forging of a helical gear of module 1.745 and 24 teeth using AISI-4120 steel. Although substantial scatter is evident in the results, making it difficult to distinguish improvements in load, the authors claim that the optimisation process reduces the peak forging force by $6 \%$ [25], using computed optimal parameters of a billet temperature of $900{ }^{\circ} \mathrm{C}$, friction coefficient of 0.05 and punch velocity of $30 \mathrm{~mm} / \mathrm{s}$ [25]. However, reducing friction coefficient to such a low value may be difficult in practical applications. A key issue with optimisation methods in general is that results are highly dependent on values of input parameters (such as boundary conditions, constitutive relations and weighting factors) set by the user and often these are not accurately known. Moreover, it is difficult to determine a global optimum as opposed to converging to a local optimum. Thus, although computer-based process parameter optimisation has the potential to be a promising method, it is a fairly new and somewhat immature field, with further improvement expected with expansion in computational capacity and the generation of accurate process and material data.

Table 1 Comparison of each method (experimental results)

\begin{tabular}{|c|c|c|c|c|c|c|}
\hline \multirow[t]{2}{*}{ Working method } & \multirow[t]{2}{*}{ Number } & \multicolumn{3}{|c|}{ Working conditions } & \multirow[t]{2}{*}{$\bar{P} *(\mathrm{MPa})$} & \multirow[t]{2}{*}{$h(\mathrm{~mm})$} \\
\hline & & $k(\mathrm{~mm})$ & $D_{i}(\mathrm{~mm})$ & $D_{k}(\mathrm{~mm})$ & & \\
\hline Process 'R. A.' & 1 & 0 & 0 & 12 & 290 & 4.2 \\
\hline Process 'R. H.' & 2 & 0 & 11 & 0 & 270 & 4.0 \\
\hline Type 'k fixed' & 3 & 0.5 & 12 & 12 & 250 & 4.2 \\
\hline Type 'k free' & 4 & 1.0 & 14 & 14 & 210 & 3.5 \\
\hline Type 'R.H.-R.A. combined' & 5 & 0 & 8 & 12 & 250 & 4.1 \\
\hline
\end{tabular}

Adapted from: [53] 


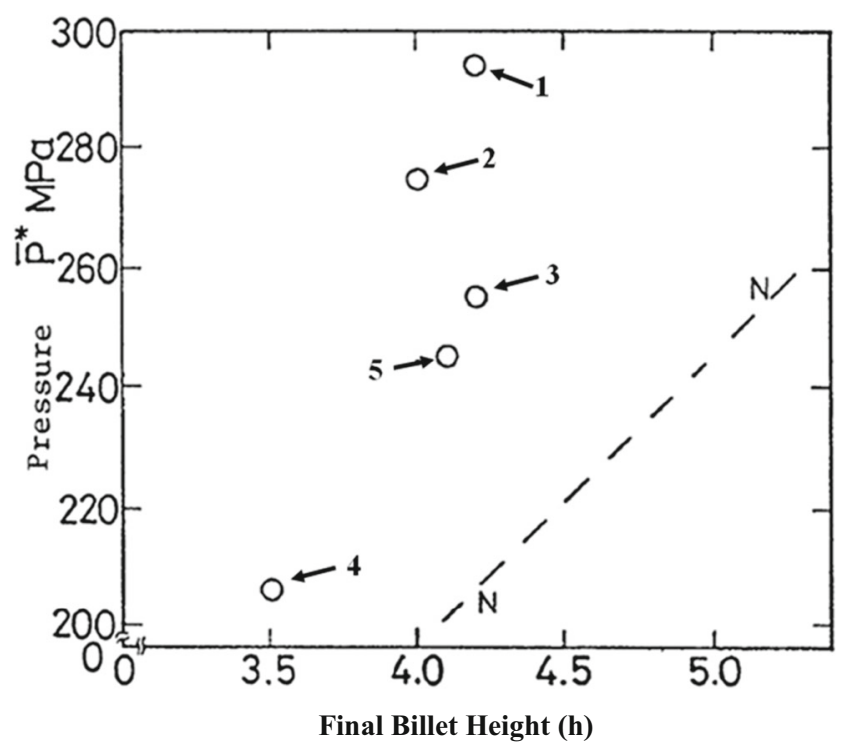

Fig. 9 A comparison of forming pressure $(P)$ and final forging height $(h)$ for the five methods shown in Table 1. Adapted from: [53]

\subsection{One step compared to two-step divided flow}

A hot forged part is seldom made in one tool, and often, cold forged parts are formed in more than one stage also. A method proposed numerous times in the literature and first by Kondo and Ohga [60], for reducing maximum force and promoting full die filling, when forging a wide flat part, is to introduce two stages in place of one, using either the relief hole or relief axis method. Kondo and Ohga proposed utilising (i) the closed die forging process to form a preform to specified dimensions and (ii) use either R.H., R.A. or flow restriction for the second step. A diagram of such a two-step method is shown in Fig. 11. Choi and Choi [7] investigated numerically and experimentally a near-net shape forging utilising Kondo and Ohga's relief axis (R.A.) and relief hole (R.H.) method which enabled the part to be formed without requiring additional machining. Qingping et al. [45] utilised a method of divided flow, somewhat similar to the R.A. method to realise lower overall loads in forging a bevel gear, as compared to a regular closed die forging. Specific details of particular implementations of two-step methods are discussed in this section.

Ohga et al. [46], the researchers behind R.H. and R.A. methods described in Sections 2.3.1 and 2.3.2, proposed using a two-step method incorporating flow relief, as a way of forming more complex components. This method is proposed as a forming process for products with a complicated circumferential shape, such as gears or splines. As described earlier in Sections 2.3.1 and 2.3.2, R.H. and R.A. methods on their own may not be entirely effective in forming a gear, as the complex gear profile could result in the filling of the relief hole and axis diameters before the gear teeth shape of the die is filled. However, it is possible to incorporate both R.H. and R.A. methods in a two-step process in order to achieve successful die filling.

Utilising a two-step forming process to extend the applicability of the R.H. and R.A. methods to complex shaped components has been shown to require 'lower forming pressure, better filling ability and higher forming precision' compared to a traditional closed die forging [61]. Experimental results obtained by Ohga et al. [46] using a two-step method in conjunction with both the R.A. and R.H. methods are shown in Fig. 12a, b respectively. They were obtained using a workpiece with similar dimensions to those in Sections 2.3.1 and 2.3.2, and a hole of similar dimensions was used for both experiments (a 12-mm-diameter hole used for the R.A. and an 11-mm hole for the R.H. method). The plots of mean pressure $\bar{p}$ vs. displacement (stroke) are shown in Fig. 12 and show the maximum pressure obtained at the end of both the first and second step (indicated by $P_{1}$ and $P_{2}$ ). In both cases, the pressure in the first stage (closed die) is restricted to be below $300 \mathrm{MPa}$, following which the workpiece is formed using either the R.A. or R.H. methods. In the second step, the R.A. and R.H. methods produce differing pressure-stroke profiles. The R.A. method requires a shorter stroke of approximately $0.8 \mathrm{~mm}$ to achieve full die filling (indicated by the black point), thus resulting in a thicker gear (i.e. less material wastage). Conversely, the R.H. method requires well over $1 \mathrm{~mm}$ of stroke to achieve full die filling, possibly indicating more material wastage.

As explained in Sections 2.3.1 and 2.3.2, forming pressure varies with the diameter of the axis or hole. For the R.A. method, an optimum diameter exists to minimise forming pressure and for the R.H. method, forming pressure reduces with increasing diameter. Therefore, in production, optimum diameters should be chosen in order to maximise filling and minimise the peak forming pressure in the two-step process.

Examples of experimental values obtained for the onestep closed die method, the two-step method with R.H. as well as two-step method with R.A., are shown in Table 2. It can be seen that the maximum pressure required for the two-step methods is approximately $50 \%$ of that for the single step closed die method for the gear geometry studied. Furthermore, it can be seen that both $P_{1}$ and $P_{2}$ values for the two-step methods are similar. This is because trials conducted by Ohga et al. [46] indicated that an increase in $P_{1}$ resulted in a decrease in $P_{2}$, and thus, the optimum process (i.e. that which minimises the maximum pressure throughout the forming) is that in which $P_{1}$ and $P_{2}$ are equal. It can also be seen that the R.A. method produces components closer to that of the singlestep method compared to the R.H. method (i.e. taller samples). Therefore, it can be seen that the R.H. and R.A. methods are equally effective in filling the die [46], as the forming pressures are the same, with the main difference being the final height of the component. 


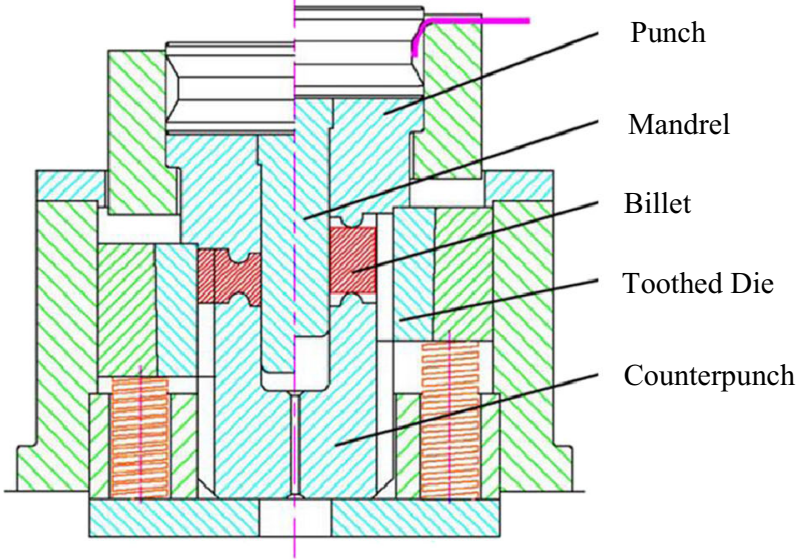

(i) Flat tooth punch and counterpunch

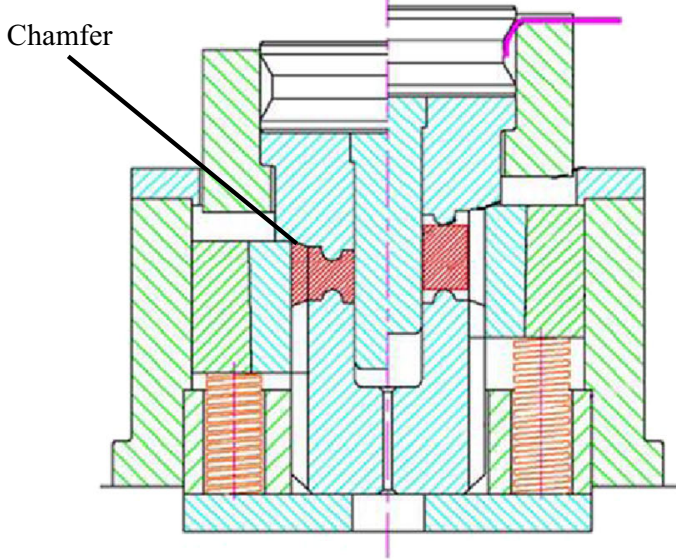

(ii) Chamfered tooth punch and counterpunch

(a) Punch and counterpunch design [23]

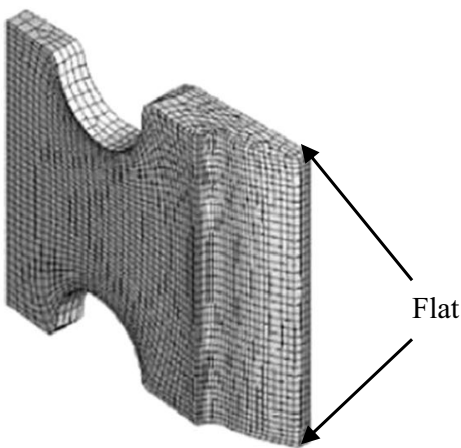

(i) Flat tooth punch and counterpunch

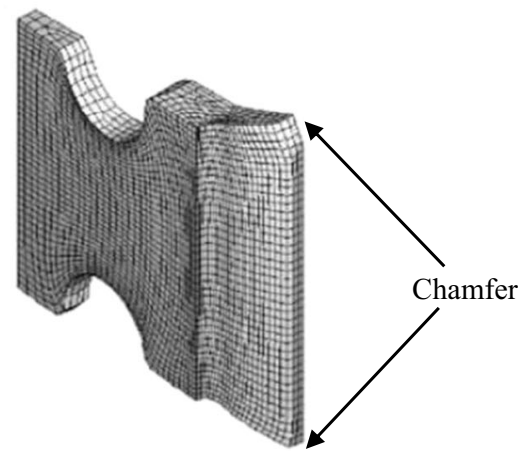

(ii) Chamfered tooth punch and counterpunch

(b) Simulation of completed tooth forging $[23,54]$

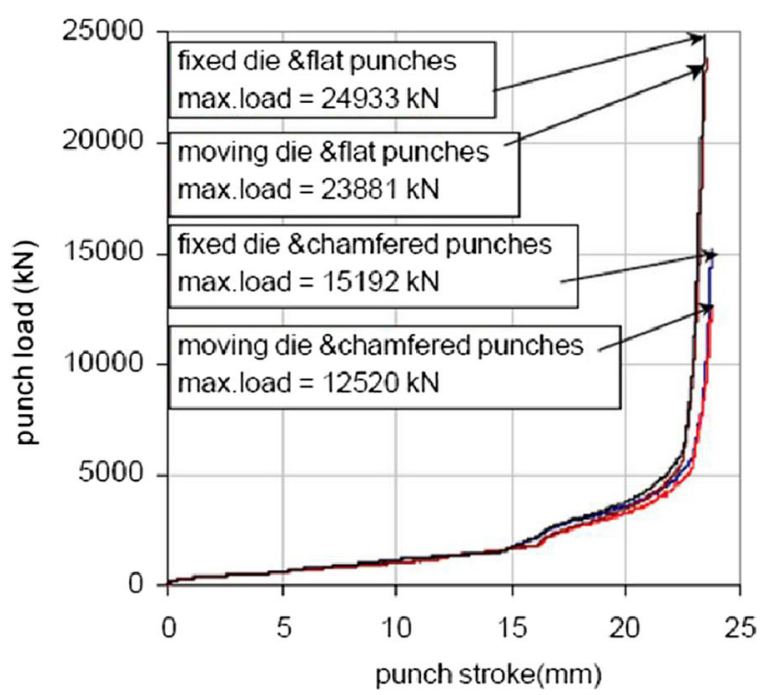

(c) Forging load comparison for different punch tooth designs [23]

Fig. 10 A comparison of the effects of flat and chamfered counterpunch and punch tool components on forging load. a Punch and counterpunch design [23]. b Simulation of completed tooth forging [23, 54]. c Forging load comparison for different punch tooth designs [23]

A two-stage process was also examined numerically and experimentally by Zhang and Xie [62] for the superplastic forming of bulk metallic glass spur gears, in which the central hole is punched out with a mandrel. Three configurations were studied (Fig. 13a): (i) a single-stage process with the mandrel in the punch, (ii) a single-stage process with the mandrel in the counterpunch, and (iii) a two-stage process in which 'the billet is compressed by a punch with short mandrel at the first stage, 
Fig. 11 Two-step forming process possibilities (adapted from $[46,60])$

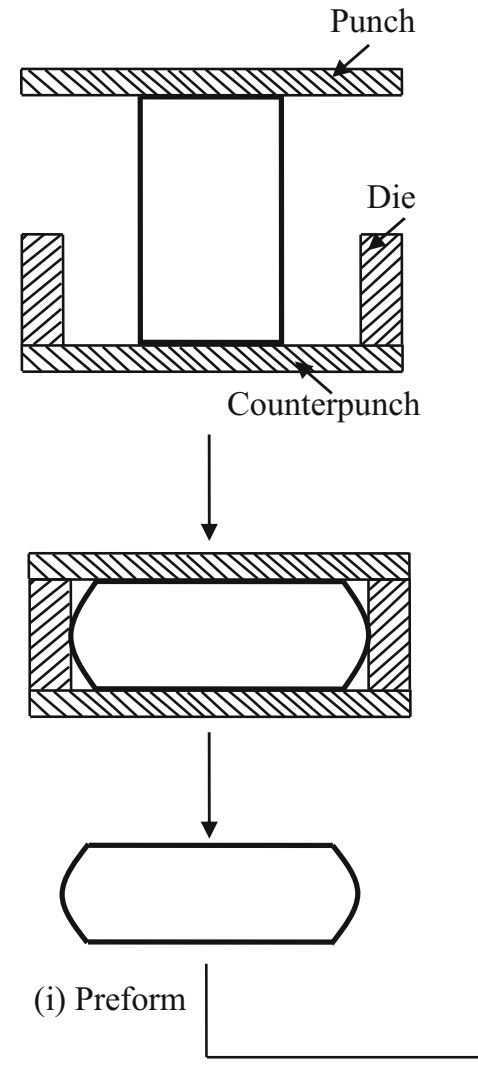

Step 1 - Forming Preform

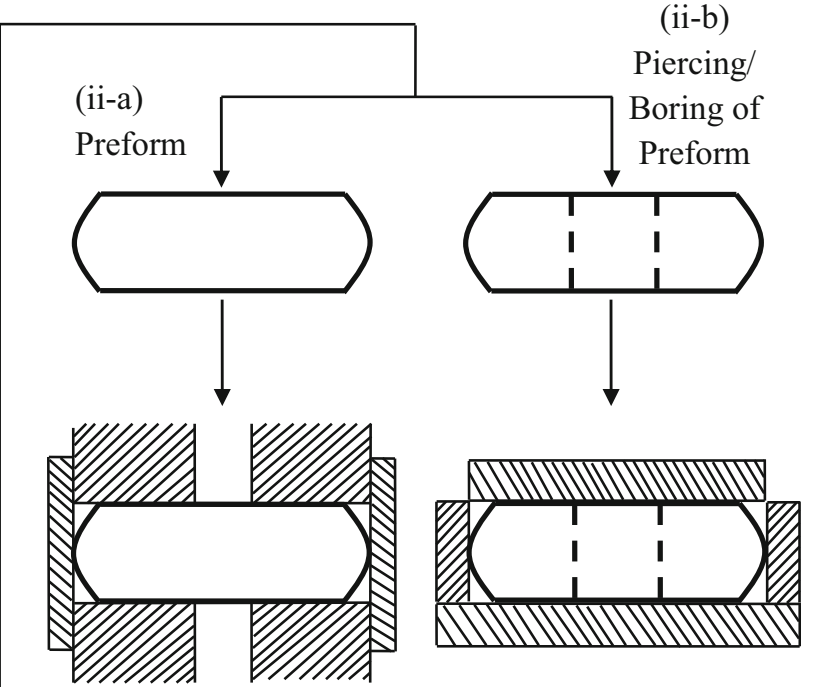

(iii-a) Relief Axis Method

Method

Step 2 - Final Forging

and then the central hole is formed by a punch with long mandrel at the second stage'. An example of the formed components with each stage is shown in Fig. 13b.

The results (Fig. 13c (i, ii)) show that the first stage of a two-stage process requires significantly less load than a single-stage process (i.e. about 12 vs. $20 \mathrm{kN}$ for the singlestage processes) [62]. FE results show that the second stage in the process requires of the order of $2.5-3 \mathrm{kN}$, although a load curve for the second stage was not provided in the paper. Experimental results showed that the maximum loads in processes A, B and C were 15, 12.8 and $12 \mathrm{kN}$ respectively [61]. According to the authors, the forming loads of the three processes are reduced by decreasing the forming strain rate, with the disadvantage of increased forming time. However, it is difficult to directly compare the final load values between each method, as the component geometry varies depending on the method used. For example, the two-stage forming process appears to incorporate both the relief axis and $\mathrm{k}$ fixed method presented in Section 2.3.2 which may serve to additionally lower the load.

Further work on two-stage processes was conducted by Jung et al. [63] for the forming of helical gears where a spur gear was first extruded followed by a second-stage extrusion and torsion process to produce a helical gear. In this study, it was found that helical gears can be produced with a forming load of $57.5 \mathrm{kN}$ while the traditional process required $330 \mathrm{kN}$ $[62,63]$. However, in the study, the extruded gear from the first stage was annealed and lubricated before continuing to the second stage, which would affect results compared to a single step process. Moreover, the load required to produce the initial spur gear preform was not mentioned in the study and hence a conclusion cannot be made on the overall percentage load reduction. In general, the principle behind multistep forming is that the tooling features can be optimised in each stage to facilitate ease of metal flow and maximise yield. Typically, the punch and counterpunch shapes are adjusted in each step to promote beneficial material flow. For the case of hot formed components, an intermittent reheat stage can be introduced to reheat or anneal components before further deformation, reducing flow stress encountered in the deformation and thus reducing forming pressure required.

\subsection{Incremental forming}

Incremental forming techniques have the potential to form components with lower loads than conventional bulk forming $[64,65]$, as loads are applied to small segments of a workpiece at a time. Several studies have been conducted into incremental forging, which demonstrates the advantages of forming using a large number of small stages [66-71]. Orbital forging 


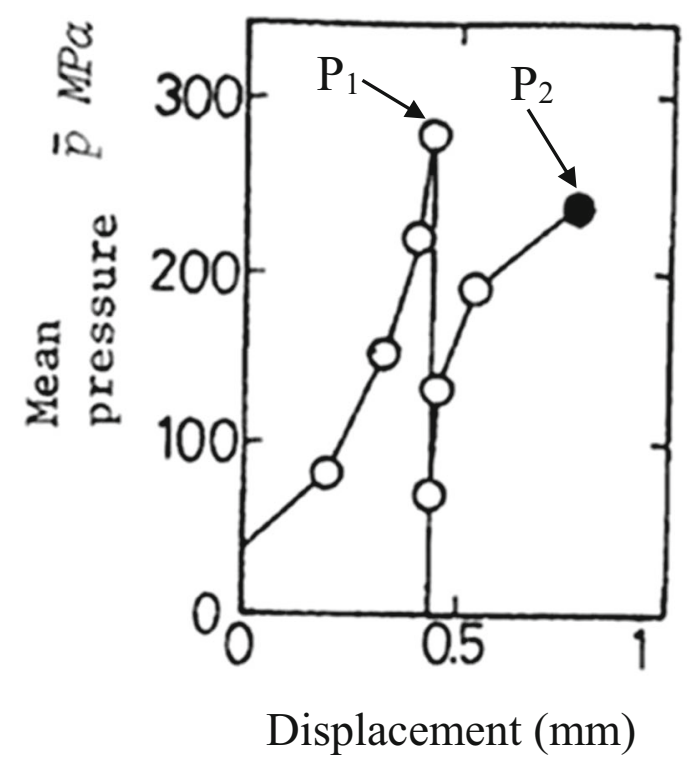

(a) Relief Axis with relief diameter $D_{i}=12 \mathrm{~mm}[46]$

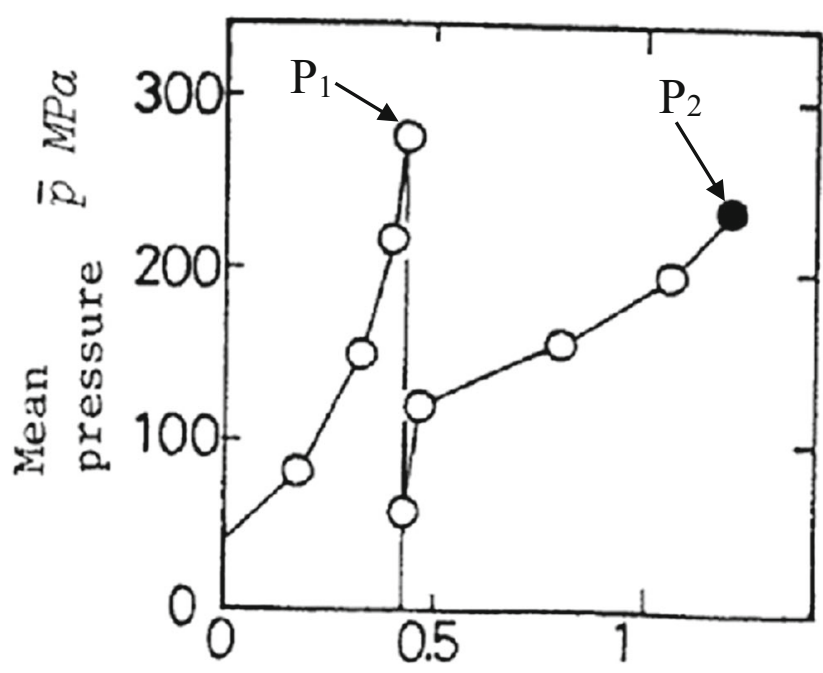

\section{Displacement (mm)}

(b) Relief Hole with relief diameter $\mathrm{D}_{\mathrm{i}}=\mathbf{1 1} \mathrm{mm}$ [46]

Fig. 12 Two-step forging method utilising relief axis (a) and relief hole (b) methods. Adapted from [46]. a Relief axis with relief diameter $D_{i}=$ $12 \mathrm{~mm}$ [46]. b Relief hole with relief diameter $D_{i}=11 \mathrm{~mm}$ [46] is a method of incremental forming in which the sample is placed between an orbiting upper die which moves towards the workpiece held in a stationary lower die, as shown in Fig. 14 [65]. In this situation, the rotation of the slightly angled upper die imparts a load on only a sector of the workpiece. As the upper die nutates, it rolls around the workpiece deforming it incrementally as it moves downward. Thus, the process is effectively a sequence of deformations of small volumes, not deformation of the whole bulk simultaneously.

This process has been applied to the forging of hubs, gears, bearing rings and bearing-end covers $[65,69,72]$, though no evidence has been found of its application to the precision forging of gears. A study on forging a sample mushroomshaped component has found that utilising the orbital forging method can reduce the maximum punch load greatly, from approximately $1900 \mathrm{kN}$ to approximately $450 \mathrm{kN}$ [65]. However, it has not been utilised in precision forging although can be used for the net shape forging of components such as synchro cones and dog teeth. An option to precision forge gear teeth could be to utilise the incremental forming technique in the first stage of a two-stage forming process, to form the bulk of the product into near-net shape, followed by a small deformation in a precision forging toolset. Orbital forging generally is too slow for mass production of hot forgings but is practical for automated cold forging.

\subsection{The KOBO method}

The KOBO method, named after its inventors Andrzej Korbel and Wlodzimierz Bochniak [73, 74], can be applied to forming processes such as forging, rolling and extrusion. Its basic principle is that the tool (i.e. the die or the punch) is oscillated in a direction other than the working direction of the process. This causes the surface of the workpiece, in contact with the die or punch due to friction, to also oscillate and hence changes the course of the plastic flow $[75,76]$. This has the effect of changing the deformation mode from homogenous fine slip into heterogenous micro-shear banding [77]. The importance of this change is that the 'global hardening rate falls to zero or even achieves a negative value' [73, 78], thus effectively 'softening' the material, improving forgeability. A schematic of the method is shown in Fig. 15a [76].
Table 2 Experimental comparison of first step and second step methods

\begin{tabular}{llll}
\hline Measurements & $\begin{array}{l}\text { Closed die } \\
\text { forging }\end{array}$ & $\begin{array}{l}\text { Closed die with } \\
\text { relief axis }\end{array}$ & $\begin{array}{l}\text { Closed die with } \\
\text { relief hole }\end{array}$ \\
\hline Relief diameter $\left(D_{i}\right)(\mathrm{mm})$ & 0 & 12 & 11 \\
1st step pressure $\left(P_{1}\right)(\mathrm{MPa})$ & N/A & 248 & 245 \\
2nd step pressure $\left(P_{2}\right)(\mathrm{MPa})$ & $>500$ & 248 & 245 \\
Final height as $\%$ of closed die, $(H) \%$ & 100 & 91 & 84 \\
\hline
\end{tabular}

Adapted from: [46] 


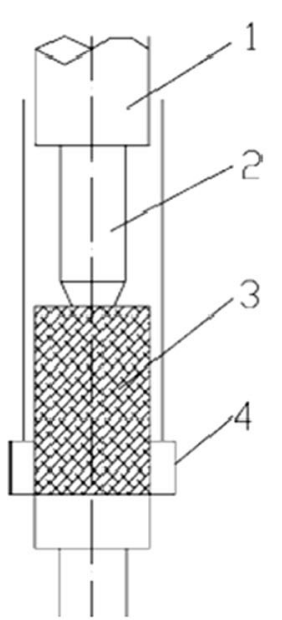

(i) Upper mandrel process

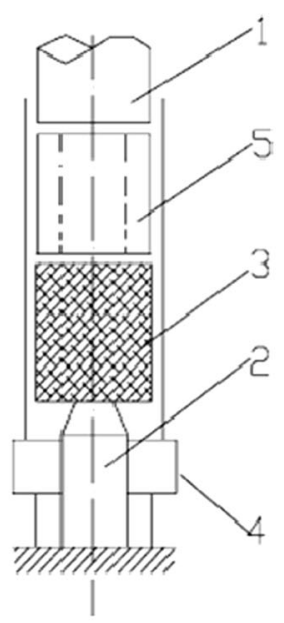

(ii) Bottom mandrel process
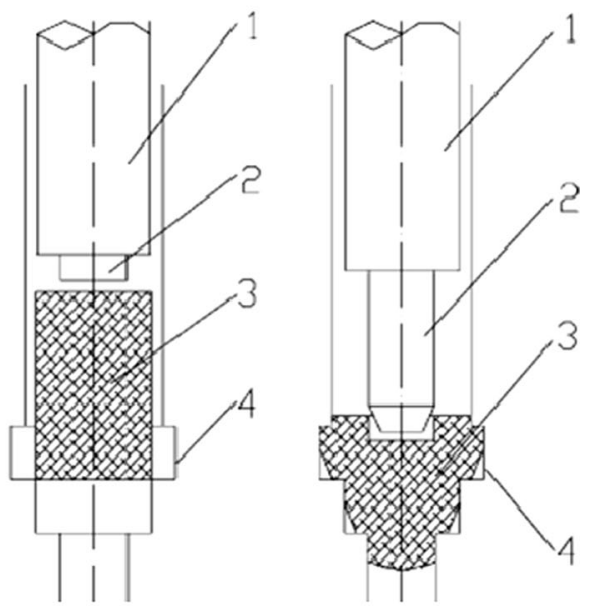

(iii) Two stage forming process

(a) Three divided material flow processes. 1- forging punch; 2 - mandrel; 3 - workpiece; 4 - die; tubiform pad

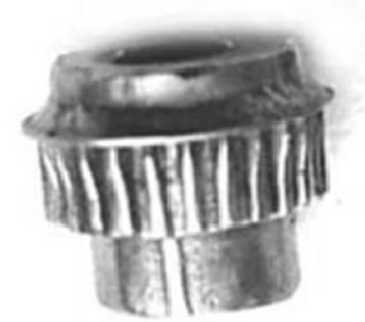

(i) Upper mandrel process

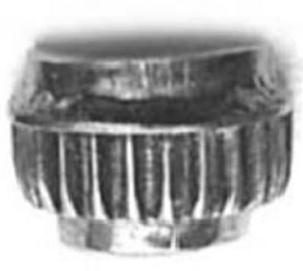

(ii) Bottom mandrel process

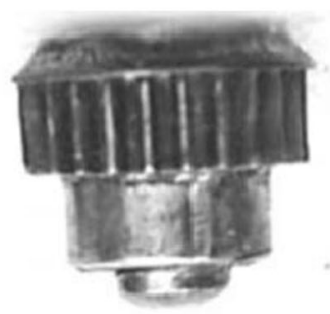

(iii) Two stage forming process

(b) Examples of each process

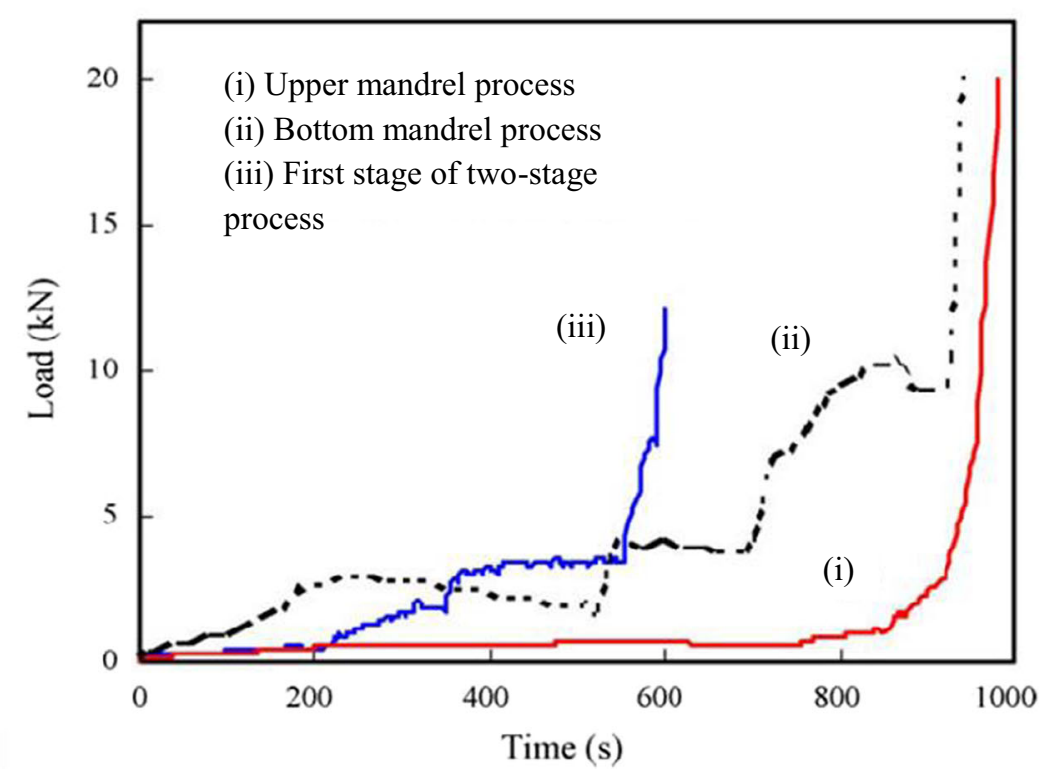

(c) Comparison of forging load for the three processes 
Fig. 13 Tool and process design to reduce forging force during two-stage process [62]. a Three divided material flow processes. 1-forging punch; 2-mandrel; 3-workpiece; 4 - die; tubiform pad. b Examples of each process. $\mathbf{c}$ Comparison of forging load for the three processes

Studies have been conducted into the application of the KOBO method to the hot forging of bevel gears from structural steel (containing $0.45 \% \mathrm{C}$ ) at temperatures between 600 and $950{ }^{\circ} \mathrm{C}[76]$. In this study, both conventional and $\mathrm{KOBO}$ forging were applied, with the $\mathrm{KOBO}$ method oscillating the punch about its axis by $\pm 4^{\circ}$ at $3 \mathrm{~Hz}$. The external torque applied to the punch and the punch load using the KOBO method are shown in Fig. 15b [76].

For this particular case, conventional forging required loads of around $7600-7800 \mathrm{kN}$, while KOBO forging required about $1850 \mathrm{kN}$ [76]. This is a significant reduction to less than a quarter of the force of conventional forging, while the mechanical properties of the forgings were found to not differ from that of conventional forging.

The benefits of applied torsion during forging were also demonstrated by Matsumoto et al. [79]. In their study, the forging load in cold upsetting was reduced by simultaneous torsional oscillation at a maximum frequency of $1.5 \mathrm{~Hz}$, superposed by an axial load. The authors concluded that load was reduced by $5 \%$ resulting from the heat generation and subsequent temperature increase of the cold workpiece during deformation and a $1^{\circ}$ rotation. Moreover, for tests with significant torsion $\left(1700^{\circ}\right.$ rotation), the forming load was reduced by approximately $80 \%$.

\subsection{Load pulsation}

The load pulsation method involves the axial vibration of tooling components during the forming stroke with the aim

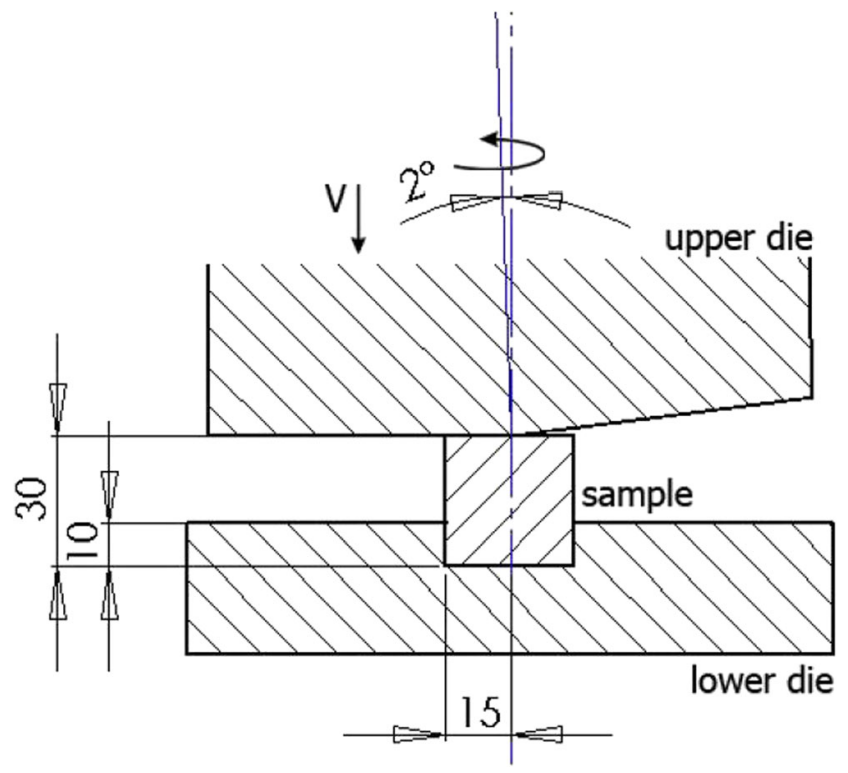

Fig. 14 Open-die orbital forging [65]

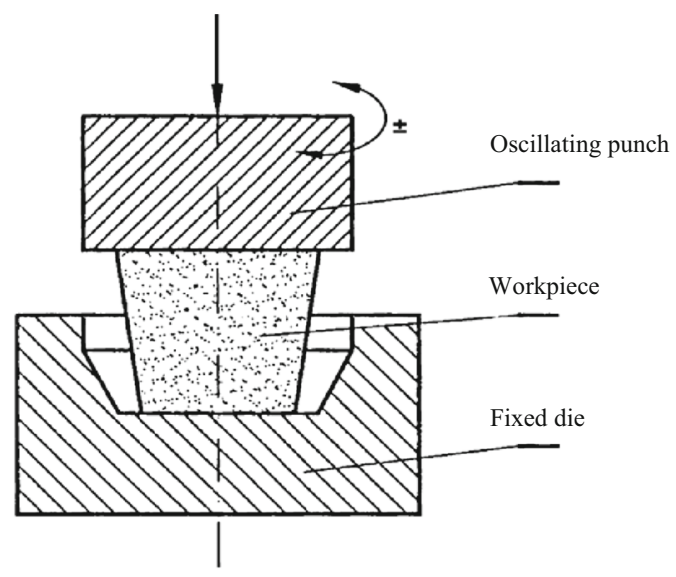

(a) KOBO forging method

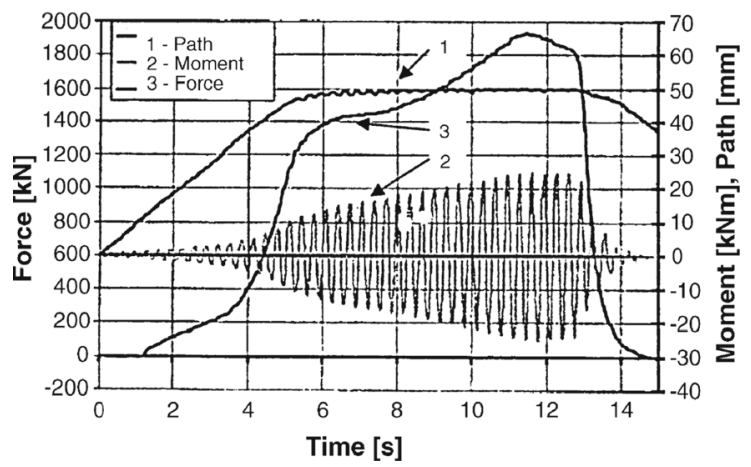

(b) KOBO forming path, moment and force

Fig. $15 \mathrm{KOBO}$ forming method and the experimental results [76]. a KOBO forging method. $\mathbf{b}$ KOBO forming path, moment, and force

of reducing friction and load [80, 81]. During traditional forming, large workpiece deformation results in lubricant thinning at the tool/workpiece interface and hence an increase in friction and forming load. In the work performed by Maeno et al. [82], a reduction in friction and forming force was achieved when forming an aluminium plate of dimensions $10 \mathrm{~mm}$ diameter and $2 \mathrm{~mm}$ thickness between an oscillating upper die (punch) and lower die (counterpunch).

The principle of operation of the load pulsation method is as follows. During deformation (Fig. 16a), the friction hill results in pressure being greatest near the centreline, and thus, the upper die (punch) and lower die (counterpunch) are elastically deformed in a concave manner, with the workpiece plastically deforming into a convex shape. However, when the forming load is releasing mid-stroke, elastic recovery between the tools and workpiece occurs resulting in a minute gap forming at the outer edges of the contact interface. By utilising a continuous supply of lubricant, some of this lubricant enters this gap effectively re-lubricating this region. Repeated incremental deformation and load relaxation results in continuous re-lubrication of the workpiece throughout the entire stroke, thus maintaining the friction coefficient at the 

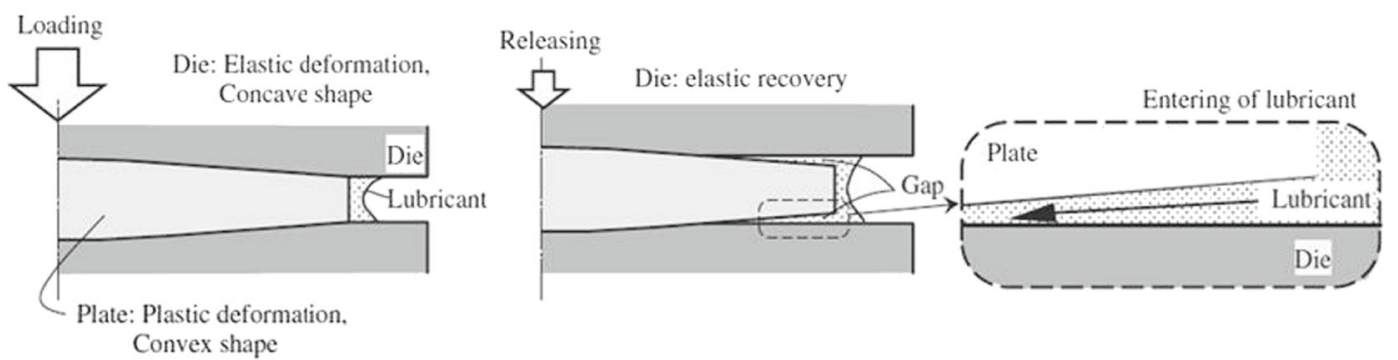

(a) Load reduction by pulsation

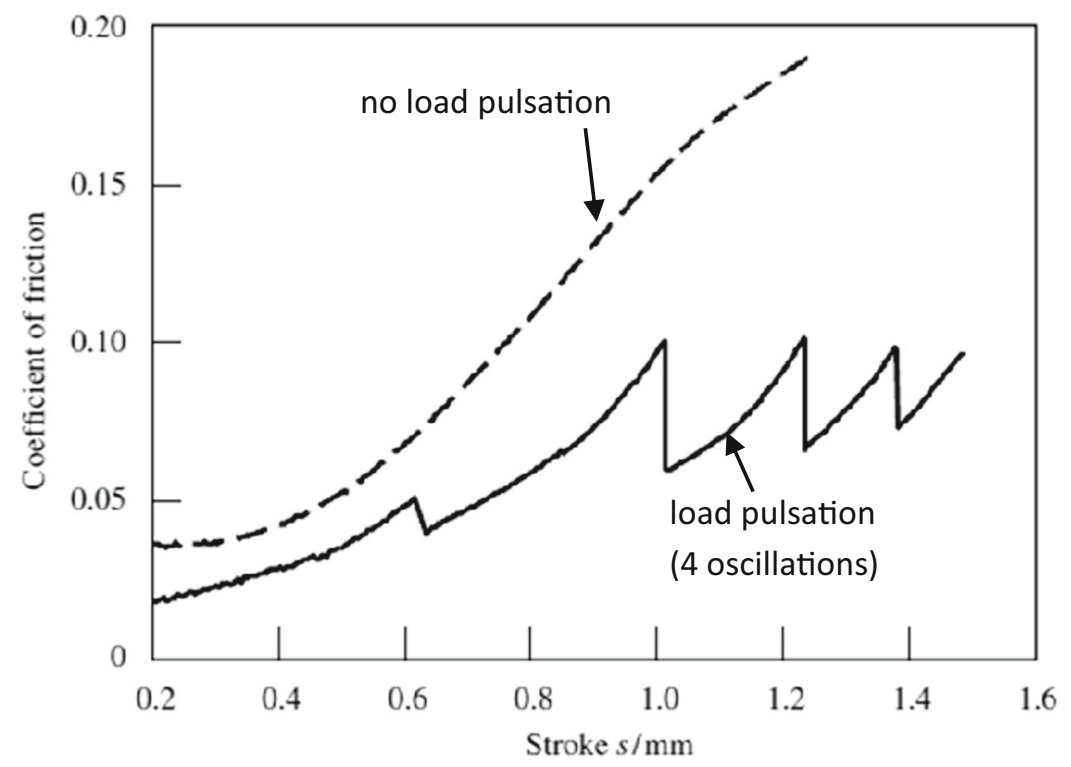

(b) Variations of coefficient of friction with stroke

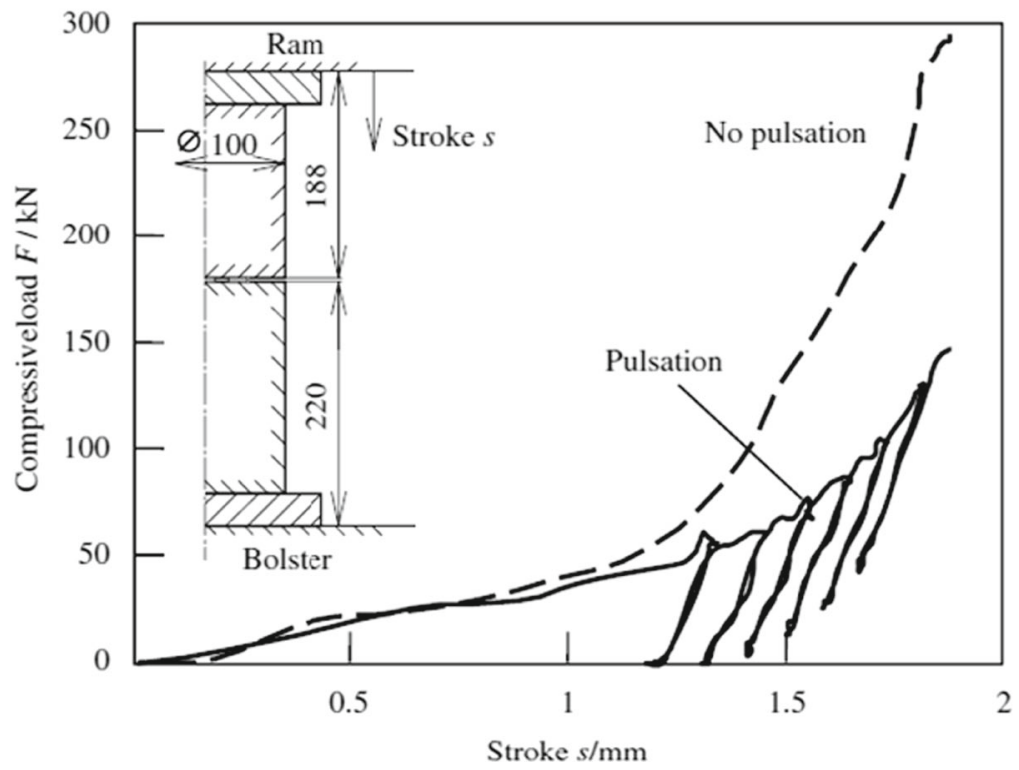

(c) Variation of compressive load with stroke

Fig. 16 Load pulsation method [82]. a Load reduction by pulsation. b Variations of coefficient of friction with stroke. $\mathbf{c}$ Variation of compressive load with stroke 
interface within controlled levels, as shown in Fig. 16b. The authors have demonstrated that utilising this method with six load pulsation oscillations, for an overall stroke of $1.9 \mathrm{~mm}$, each with a $0.15-\mathrm{mm}$ upstroke followed by a $0.23-\mathrm{mm}$ downstroke, the forming force can be reduced by approximately $50 \%$ from 300 to $150 \mathrm{kN}$ as shown in Fig. 16c. A similar force reduction effect was also confirmed in studies involving ferritic stainless plate [83] of $3 \mathrm{~mm}$ thickness and $14 \mathrm{~mm}$ in diameter and in processes such as backward extrusion [84].

While a significant force reduction can be achieved utilising load pulsation, the process is only effective due to the continuous re-lubrication of the tool/workpiece interface. For forming operations that do not utilise any lubricants, this method would be ineffective. Moreover, existing literature has focused on a limited range of workpiece geometries such as sheets and plates, and thus, further study is required on the effectiveness of this method on larger thickness workpieces.

\section{Discussion}

All the methods presented in this paper have been studied in a scientific context, and it is evident that advantages and drawbacks relate to each one regarding its industrial viability and this is discussed below. Examples of percentage reduction in load are given for most methods as a guide. However, no examples of the same part being made by different methods exist, so that an exact comparison of process characteristics cannot be made.

The methods classified under workpiece design are as follows: (i) preform optimisation, (ii) relief hole and (ii) relief axis. Commonly, preform optimisation is used to eliminate defects for example, folding, to produce desirable flow patterns, or to maximise yield or to enhance microstructure. For hollow parts, using a hollow preform in the finishing die will reduce load compared with a solid one as used in conventional hot forging, as the high pressure required to forge a thin central web (to be pierced out later) is eliminated. Figure 17 shows a forged hollow automotive gear with synchro cone and dog teeth. Extrusion of the cone facilitates dog teeth formation as it acts in a similar way to a relief axis and a moveable die enhance lower tooth point formation [85]. While preform optimisation is effective for these objectives, its utility in terms of reducing maximum load encountered in a traditional closed die forging operation is unclear, as unless a hollow one replaces a solid workpiece, or by using one, a significantly different flow pattern in the finishing die results, the same final load will be required for final filling regardless of initial workpiece shape, assuming that the material does not strain harden, maintains a constant temperature throughout the process and no metallurgical changes occur during a two-stage process. Preforms are typically designed based upon experience, whereas the methods presented in the literature here use scientific methods

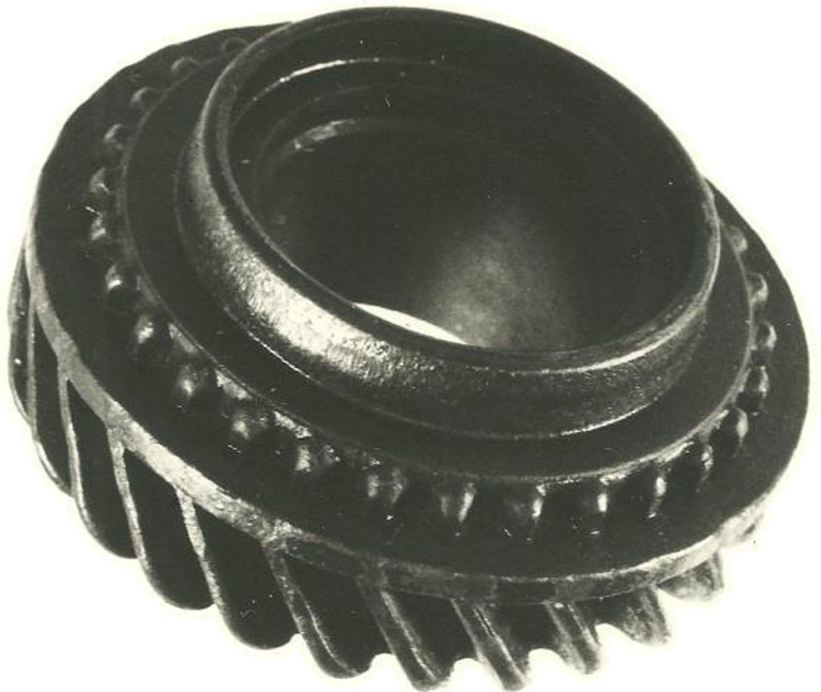

Fig. 17 Helical spur gear with synchro cone and dog teeth forged from a hollow preform in a completely closed die cavity [85]

such as neural networks and statistical loss functions [33, 35-38]. In the literature, these have been demonstrated to be able to reduce maximum loads encountered during forging and minimise waste material. These methods can seemingly be applied to a wide range of parts, with no obvious disadvantage other than a preform being costlier, due to prior manufacturing operations required to produce the preform shape compared to standard supplied billet material, but this is compensated for by increased yield and, often, improved die life. Two common issues with optimisation studies are as follows: (i) many are based upon optimising a user-defined geometry, where a designer's first choice of input shape affects results, so the results are biased, and (ii) it is uncertain if an optimisation results to an overall global optimum or converges to a local optimum close to the input conditions.

The relief hole method [22] has been demonstrated to reduce load in gear forging by enabling both radially inward and outward flow simultaneously. While it has been shown to be very effective in reducing forming load, the consequences of this method are as follows: (i) material wastage, should a hole be drilled or pieced in the workpiece, although this will have to be done for most finished gears; (ii) additional preform operations, should the hole be produced by extrusion and piercing of the workpiece; and (iii) limited applicability to shapes which have a complex outer shape (i.e. gears with long teeth), as the material would be more prone to filling the central hole than filling the outside shape. Moreover, its applicability is limited to components which have a centrally located hole, as it cannot be used to forge solid parts. In addition, the central hole which remains after forging would not be perfectly concentric within the part, perfectly circular or of constant diameter requiring additional machining and a further operational step in production, although this is preferable to producing a hole in a solid part. 
Although strictly a method of tooling design, an extension of the relief hole principle involves restricting the inwards flow through the use of a protruding stud [53]. This has the effect of improving the corner filling issue with complex external shapes present in the relief hole method alone. Utilisation of this requires additional mandrels which may be moveable depending on the particular implementation of R.A. chosen, hence increasing complexity and tooling cost.

The relief axis principle $[21,22]$ can be classified as both a workpiece and a tool design method, as it requires modified tooling as well as utilising the relief hole method. Numerical and experimental investigation has proven the method to result in comparably less material wastage and a lower load than relief hole. It largely has the same advantages and disadvantages as the relief hole method, at the expense of slightly more complex tooling. Moreover, the relief axis method has the potential to produce solid components with a small integral shaft, although more efficient processes such as heading from a long bar are recommended for integral shafts. Similarly to use of the relief hole method, limitations exist when using the method to produce parts with a complicated external shape (e.g. gears) as there is the potential to promote inwards material flow than outwards due to the presence of a central hole. This can be alleviated by variants of the R.A. method such as type $\mathrm{k}$ free and type $\mathrm{k}$ fixed.

Methods of force reduction involving tooling design include the following: (i) punch and counterpunch design, (ii) floating or axially driven dies which can control the vertical direction of friction, (iii) flow restriction to restrict radially inward flow and (iv) chamfered punch/counterpunch. Variations in the tooling arrangement resulting in reduced load are commonly known. Studies in gear forging have shown that utilising a moving die as opposed to a fixed die can reduce the overall load by $21 \%$, due to reduced friction between the workpiece material and the die [23].

Varying the profiles of the punch and counterpunch has been examined, with a $\mathrm{W}$-shaped punch and inverted Vshaped counterpunch being used as opposed to flat surfaces for gear forging with the result being minimised barrelling, thus more effective corner filling of the die cavity [49]. Although its effect on final filling load is uncertain, the method appears to be effective at its aim of improving corner filling, while requiring only modest redesign of tools. However, the usefulness of this method may be limited in practice by specification of forged shape. It has also been shown [50] that using a bi-directional forging with driven punch and counterpunch can reduce the working load in a similar way to using a floating die. In this arrangement, the moving punch and counterpunch frictional effects act towards the mid-height of the component, assuming shape symmetry, from the top and bottom surfaces, thus effectively halving the peripheral area over which it acts. Obviously, this set-up adds to tooling cost.
Specifically in the case of gear forging, utilising a chamfer or angle on the punch and counterpunch to provide a compensation space substantially reduces the load required to fill the corners of tooth tips, with a load reduction of $39-49 \%$ observed [23]. The chamfered punch and counterpunch components would cause the axial forging load to have a force component in the radially outward and upward direction, thus aiding flow into the corners. This method is attractive, as no changes to the equipment other than simple modifications to the punch and the counterpunch are necessary. An obvious downside to this method is that an additional post-forging machining process is necessary to remove the excess material.

Studies into independently oscillating the die axially at frequencies in the region of $0.1 \mathrm{~Hz}$, intended to reduce the frictional force, have been shown to reduce punch pressure substantially $[51,52]$. Such a method requires an oscillating mechanism, adding complexity to the toolset. Moreover, it is likely to be applicable only to parts with a constant cross section along their axis, such as shafts or spur gears. Applicability to parts with a changing cross section (i.e. helical gears) may be limited by the increased complexity to the tooling as this would require the die to oscillate with helical motion.

Presented process design methods are as follows: (i) process parameter optimisation, (ii) multi-stage forming, (iii) incremental forming and the (iv) the KOBO and (v) load pulsation tool oscillation methods. Process parameter optimisation, similar to preform optimisation, is something which is often experience-based in practice. The studies presented in this paper describe scientific methods of optimisation which have the potential to ensure that the most of the process parameters are optimised on any occasion [25, 58]. In terms of reducing forming load, the optimisation of parameters such as ram speed and temperature holds promise in promoting full filling of complex parts. However, more study is needed to determine whether the methods can effectively and reliably reduce the overall load for a range of formed component shapes.

Multi-stage forming, by producing an optimised preform to the finishing die, is commonly used to form components with complex shapes which if made in one operation would either contain flow faults or result in low material yield. However, the literature presented here demonstrates that by utilising multi-stage forming, load can be substantially reduced compared to a single-stage, with studies claiming reductions of $60-80 \%[62,63]$ for the geometries used. Two-stage forming has been examined in conjunction with the relief hole and relief axis methods, enabling full filling of a gear die with relatively low punch pressure. The optimum existed where the maximum pressure in the first and second stage was equal [46] although the technique was only examined for forged disc shapes. While a large number of publications have proven the effectiveness of a multi-stage forming at reducing forging load, such a method is not without caveats. Utilising this results in substantially increased tooling cost, as, for mass 
production, wide bed presses for the multi-stage tools, and normally, automated in-press handling is required. In addition, for cold forging processes, often interstage workpiece annealing is necessary to eliminate work hardening, followed by relubrication.

Incremental forming, such as orbital forging, is a classical technique and has a proven effectiveness in lowering average load, as pressure is applied only to a small portion of the workpiece at any time; reductions in load of over $70 \%$ have been observed in research [65]. However, although this method has been applied to forging of hubs, gears, bearing rings and bearing-end covers, little study has been performed on the precision forging of components such as gears. In addition, the slowness of orbital forging does not favour it for hot working operations.

The KOBO method operates by rapidly oscillating the tool (i.e. the punch) in a direction different to that of the forging direction. By changing the mode of deformations, the hardening rate of the material is greatly reduced $[73,78]$, thus reducing the overall working force. According to the inventors, this method can reduce forming loads by approximately $75 \%$ [76] for forged bevel gears. Utilisation of this method requires installation of an additional high speed drive which can oscillate the tool at a frequency in the range of $3 \mathrm{~Hz}$ [76]. Depending on the size and shape of the component being produced, this method may not be entirely practicable.

In contrast to the KOBO method, the load pulsation method operates by oscillating the punch and counterpunch in the same direction as the forging direction. The cyclic unloading of the deformed workpiece results in elastic recovery of the tools enabling re-lubrication of the high workpiece deformation regions [82-84], thus reducing the overall working force. For the forging of plates, this method has demonstrated a load reduction of up to 50\% [82] compared to non-oscillating tools. The method is limited to operations utilising lubricants, and the effectiveness on large thickness workpieces and complex profiles is yet to be determined.

\section{Conclusions}

A review of the methods available suggests that an effective means of reducing forging load is to combine a flow restriction method in conjunction with relief hole and a moving die toolset incorporating a chamfered punch/counterpunch. Results obtained for the reviewed methods suggest that load reduction could be by over $60 \%$. However, the selection of any method, or combination of methods, to reduce forming loads and pressures or increase filling in the tool is highly dependent on the geometry of the component to be formed as well as industrial constraints such as productivity, material utilisation and dwell time and thus there is no single method usable for all situations.
Therefore, it is difficult to directly compare the methods for load reduction in precision forging and quantify the benefit of individual methods, since different workpiece/test-piece geometries were used in the various studies reported in the literature. Benchmark tests should be designed for different load reduction methods, which would enable a direct comparison and suitable recommendations to be made for individual applications.

Thus, it is of the authors' opinion that in the future, the development of an expert software system, enabling a user to upload their component shape geometry and processing parameters, would allow a comparison to be made with each of the reviewed load reduction methods. In this way, a recommendation can be made for the best individual or combined load reduction method to assist the user in selecting an appropriate tool design arrangement and billet geometry.

Publisher's note

Springer Nature remains neutral with regard to jurisdictional claims in published maps and institutional affiliations.

Open Access This article is distributed under the terms of the Creative Commons Attribution 4.0 International License (http:// creativecommons.org/licenses/by/4.0/), which permits unrestricted use, distribution, and reproduction in any medium, provided you give appropriate credit to the original author(s) and the source, provide a link to the Creative Commons license, and indicate if changes were made.

Publisher's Note Springer Nature remains neutral with regard to jurisdictional claims in published maps and institutional affiliations.

\section{References}

1. Behrens BA, Knigge J (2010) EU Project MagForming: development of a magnesium forging process for aeronautical applications, from the conference Magnesium: 8th International Conference on Magnesium Alloys and their Applications, ISBN: 978-3-52732732-4

2. Samanta SK (1976) Helical gear: a noble method of manufacturing it, Proceedings $4^{\text {th }}$ North American Metalworking Research Conference, Battele's Columbus Labs, Columbus, Ohio, USA, Society of Manufacturing Engineers, pp. 199-205

3. Choi J, Cho H, Kwon H (1994) A new extrusion process for helicalgears: experimental study. J Mater Process Technol 44(1-2):35-53

4. Choi JC, Choi Y (1998) A study on the forging of external spur gears: upper-bound analyses and experiments. Int $\mathrm{J}$ Mach Tool Manu 38(10-11):1193-1208

5. Mathas K (2005) Forging ahead for gear applications, Gear Solutions, Accessed Online (6/5/13) at http://gearsolutions.com/ article/detail/5550/title/forging-ahead-for-gear-applications

6. Yang TS (2009) Prediction of maximum forming load and billet dimensions using an abductive network and finite element method simulation of a near net-shaped helical gear forging. Proc Inst Mech Eng, Part B: J Eng Manuf 233(3):289-301

7. Choi JC, Choi Y (1999) Precision forging of spur gears with inside relief. Int J Mach Tool Manu 39(10):1575-1588 
8. Alves ML, Rodrigues JMC, Martins PAF (2001) Cold forging of gears: experimental and theoretical investigation. Finite Elem Anal Des 37(6-7):549-558

9. Doege E, Nagele H (1994) FE simulation of the precision forging process of bevel gears. CIRP Ann Manuf Technol 43(1):241-244

10. Dean TA (2000) The net-shape forming of gears. Mater Des 21(4): 271-278

11. Shan DB, Xu WC, Lu Y (2004) Study on precision forging technology for a complex shaped light alloy forging. J Mater Process Technol 151(1-3):289-293

12. Jin J, Xia JC, Wang XY, Hu GA, Liu H (2009) Die design for cold precision forging of bevel gear based on finite element method. $\mathrm{J}$ Cent S Univ Technol 16(4):546-551

13. Miller RC (1967) Pneumatic-mechanical forging-state of the art, The First International Conference of the Centre for High Energy Forming. University of Denver, Estes Park

14. Moriguchi I (1992) Cold forging of gears and other complex shapes. J Mater Process Technol 35(3-4):439-450

15. Tuncer C, Dean TA (1988) Precision forging hollow parts in novel dies. J Mech Work Technol 16(1):39-50

16. Tuncer C, Dean TA (1985) Die design alternatives for precision forging in completely closed die cavities, Proceedings of the 25th International Machine Tool Design and Research Conference., Birmingham, April 1985, pp. 479-483

17. Sadeghi MH, Dean TA (1990) Analysis of ejection in precision forging. Int J Mach Tools Manuf 30(4):509-519

18. Ibhadode AOA, Dean TA (1988) Corner filling characteristics in precision forging. Int J Mach Tools Manuf 28(2):103-122

19. Tuncer C, Dean TA (1987) Die design alternatives for precision forging hollow parts. Int J Mach Tools Manuf 27(1):65-76

20. Hu CL, Liu QK, Zhao Z, Chen J, Wu GM (2010) Two step forging process of spur gear based on rigid parallel motion. J Shanghai Jiaotong Univ (Science) 15(2):241-244

21. Kim YJ, Chitkara NR (2001) Determination of preform shape to improve dimensional accuracy of the forged crown gear form in a closed — die forging process. Int J Mech Sci 43(3):853-870

22. Ohga K, Kondo K, Jitsunari T (1982) Research on precision die forging utilizing divided flow (second report, experimental study of processes utilizing flow relief-axis and relief-hole). Bulletin of JSME 25(209):1836-1842

23. Ohga K, Kondo K (1982) Research on precision die forging utilizing divided flow first report, theoretical analysis of processes utilizing flow relief-axis and relief-hole. Bull JSME 25(209):1828-1835

24. Cai J, Dean TA, Hu ZM (2004) Alternative die designs in net-shape forging of gears. J Mater Process Technol 150(1-2):48-55

25. Hu ZM, Dean TA (2000) Some aspects of net-shape forging of gears, in: Proceedings of the Second International Seminar on Precision Forging, Osaka

26. Wei FENG, Lin HUA (2011) Multi-objective optimization of process parameters for the helical gear precision forging by using Taguchi method. J Mech Sci Technol 25(6):1519-1527

27. Feng W, Hua L, Han XH (2012) Finite element analysis and simulation for cold precision forging of a helical gear. Journal of Central South University 19:3369-3377

28. Hansen N (1977) The effect of grain size and strain on the tensile flow stress of aluminium at room temperature. Acta Metall 25:863-869

29. Abdel-Rahman ARO, Dean TA (1981) The quality of hot forged spur gear forms. Part 1: mechanical and metallurgical properties. Int J Mach Tool Des Res 21(2):109-127

30. Yang, T. S., Chang, S. Y., Wang, J. H., (2010) Predictions of maximum forging load and effective stress for strain-hardening material of near net-shape helical gear forging, 2010 2nd International Conference on Computer Engineering and Technology (ICCET), Vol. 6, pp. 628

31. Altan T, Ngaile G, Shen G (2004) Cold and hot forging: fundamentals and applications, ASM International, ISBN: 0-87170-805-1
32. Ogawa N, Shiomi M, Osakada K (2002) Forming limit of magnesium alloy at elevated temperatures for precision forging. Int $\mathrm{J}$ Mach Tool Manu 42(5):607-614

33. Reza Kashyzadeh K, Amiri Asfarjani A, Hosseinzade A, Hossein Pour K (2012) Numerical investigation of the influence of friction, module and number of teeth in forging process of a spur gear. Adv Mater Res 472:2116-2120

34. Hu Y, Wang L, Politis DJ, Masen MA (2017) Development of an interactive friction model for the prediction of lubricant breakdown behaviour during sliding wear. Tribol Int 110:370-377

35. Shao Y, Lu B, Ou H, Ren F, Chen J (2014) Evolutionary forging preform design optimization using strain-based criterion. Int $\mathrm{J}$ Adv Manuf Technol 71:69-80

36. Sedighi M, Tokmechi S (2008) A new approach to preform design in forging process of complex parts. J Mater Process Technol 197(1):314-324

37. Han CS, Grandhi RV, Srinvasan R (1993) Optimal design of forging die shapes using nonlinear finite element analysis. Am Inst Aeronaut Astronaut J 31(4):774-781

38. Zhao G, Ma X, Zhao X, Grandhi RV (2004) Studies on optimization of metal forming processes using sensitivity analysis methods. J Mater Process Technol 147(2):217-228

39. Zhao G, Wright E, Grandhi RV (1995) Forging preform design with shape complexity control in simulating backward deformation. Int J Mach Tools Manuf 35:1225-1239

40. Teterin GP, Tarnovsky IJ, Chechik AA (1966) Criterion of complexity of the configuration of forgings. Kuznechno-Shtanmpovochnoe Proizvodstvo 7:6-8 (in Russian)

41. Chitkara NR, Bhutta MA (1996) Near-net shape forging of spur gear forms: an analysis and some experiments. Int J Mech Sci 38(8):891-916

42. Tong S, Muramatsu T, Mun CC, Xia AS, Enggalhardjo M, (2001) Precision cold forging-innovative methods for working pressure reduction. SIMTech Technical Reports, PT/01/042/PMF

43. Kondo K, Jitsunari T, Ohga K (1985) Investigations on cold die forging of a gear utilizing divided flow (1st report, examination of applicable condition for spur gear). Bulletin of JSME 28(244): 2442-2450

44. Avitzur B (1969) Limit analysis of disc and strip forging. Int J Mach Tool Des Res 9(2):165-195

45. Qingping Z, Huanyong C, Yuzeng W (2010) Process design for cold precision forging of bevel gear, from the conference. International Conference on Digital Manufacturing \& Automation, pp. 114-116

46. Ohga K, Kondo K, Jitsunari T (1982) Research on precision die forging utilizing divided flow (3rd report, study on an optimum combination by 'two step method' proposed anew). Bull JSME 25(209):1843-1850

47. Tuncer C, (1985) Precision forging hollow parts, Ph.D. Thesis, Department of Mechanical Engineering, University of Birmingham, UK

48. Hu C, Wang K, Liu Q (2007) Study on a new technological scheme for cold forging of spur gears. J Mater Process Technol 187:600-603

49. Song JH, Im YT (2007) Process design for closed-die forging of bevel gear by finite element analyses. J Mater Process Technol 192:1-7

50. Osakada K, Wang X, Hanami S (1997) Precision forging of spline by flashless die forging with axially driven die. CIRP AnnalsManufacturing Technology 46(1):209-212

51. Wang X, Osakada K, Hanami S (1996) Net shape forging process with axially driven container, In Proceedings of the 5th International Conference on Technology for Plasticity, Vol. 1, pp. 429-432

52. Ohga K, Kondo K, Jitsunari T (1983) Research on precision die forging utilizing divided flow (4th report, influence of restricting a centripetal flow). Bulletin of JSME 26(218):1434-1441 
53. Cai J, (2001) Precision forging and post processing of spur gears, $\mathrm{PhD}$ Thesis, The University of Birmingham, UK

54. Lee SR, Lee YK, Park CH, Yang DY (2002) A new method of preform design in hot forging by using electric field theory. Int $\mathrm{J}$ Mech Sci 44(4):773-792

54. Cai J, (2001) Precision forging and post processing of spur gears, $\mathrm{PhD}$ Thesis, The University of Birmingham, UK

55. Kim C, Park CW (2006) Development of an expert system for cold forging of axisymmetric product. Int J Adv Manuf Technol 29:459474

56. Zhu F, Wang Z, Lv M (2016) Multi-objective optimization method of precision forging process parameters to control the forming quality. Int J Adv Manuf Technol 83:1763-1771

57. Wu CY, Hsu YC (2002) Optimal shape design of an extrusionforging die using a polynomial network and a genetic algorithm. Int J Adv Manuf Technol 20:128-137

58. Chen X, Jung D (2008) Gear hot forging process robust design based on finite element method. J Mech Sci Technol 22(9):17721778

59. Oktem H, Erzurumlu T, Uzman I (2007) Application of Taguchi optimization technique in determining plastic injection molding process parameters for a thin-shell part. Mater Des 28(4):12711278

60. Kondo K, Ohga K (1995) Precision cold die forging of a ring gear by divided flow method. Int J Mach Tools Manuf 35(8):1105-1113

61. Zhang ZH, Liu XH, Xie JX (2005) Super-plastic die forging of fine precision spur gear of Zr-based bulk metallic glass. Chin J Mech Eng 41(3):151-154

62. Zhang Z, Xie J (2006) A numerical simulation of super-plastic die forging process for Zr-based bulk metallic glass spur gear. Mater Sci Eng A 433(1):323-328

63. Jung SY, Kang MC, Kim C, Kim CH, Chang YJ, Han SM (2009) A study on the extrusion by a two-step process for manufacturing helical gear. Int J Adv Manuf Technol 41(7-8):684-693

64. Hartley P, Pillinger I (2006) Numerical simulation of the forging process. Comput Methods Appl Mech Eng 195(48):6676-6690

65. Nowak J, Madej L, Ziolkiewicz S, Plewinski A, Grosman F, Pietrzyk M (2008) Recent development in orbital forging technology. Int J Mater Form 1(1):387-390

66. Guangchun W, Guoqun Z (2002) Simulation and analysis of rotary forging a ring workpiece using finite element method. Finite Elem Anal Des 38(12):1151-1164

67. Liu G, Yuan SJ, Wang ZR, Zhou DC (2004) Explanation of the mushroom effect in the rotary forging of a cylinder. J Mater Process Technol 151(1):178-182

68. Groche P, Fritsche D, Tekkaya EA, Allwood JM, Hirt G, Neugebauer R (2007) Incremental bulk metal forming. CIRP Annals-Manuf Technol 56(2):635-656
69. Li G, Jinn JT, Wu WT, Oh SI (2001) Recent development and applications of three-dimensional finite element modeling in bulk forming processes. J Mater Process Technol 113(1):40-45

70. Hirt G, Kopp R, Hofmann O, Franzke M, Barton G (2007) Implementing a high accuracy multi-mesh method for incremental bulk metal forming. CIRP Annals-Manuf Technol 56(1):313-316

71. Bruschi S, Casotto S, Dal Negro T, Icarelli R (2005) Modelling material behaviour in incremental bulk forming processes, Proceedings of the 8th International Conference on Technology of Plasticity, October 2005, Verona

72. Munshi M., Shah K., Cho H., Altan T., Finite element analysis of orbital forming used in spindle/inner ring assembly, Proceedings of the 8th International Conference on Technology of Plasticity, October 2005, Verona, Italy

73. Korbel A, Bochniak W (2004) Refinement and control of the metal structure elements by plastic deformation. Scr Mater 51(8):755-759

74. Korbel A, Bochniak W (2000) Method of plastic forming of materials, U.S. Patent No. 5,737,959 (1998). European Patent No 0711210

75. Oliferuk W, Korbel A, Bochniak W (2001) Energy balance and macroscopic strain localization during plastic deformation of polycrystalline metals. Mater Sci Eng A 319:250-253

76. Bochniak W, Korbel A, Szyndler R, Hanarz R, Stalony-Dobrzański F, Błaż L, Snarski P (2006) New forging method of bevel gears from structural steel. J Mater Process Technol 173(1):75-83

77. Korbel A (1998) CISM courses and lectures, vol 268. Springer Wien, New York, p 21

78. Korbel A, Martin P (1988) Microstructural events of macroscopic strain localization in prestrained tensile specimens. Acta Metall 36(9):2575-2586

79. Matsumoto R, Kou J, Utsunomiya H (2017) Reduction in axial forging load by low-frequency torsional oscillation in cold upsetting. Int J Adv Manuf Technol 93:933-943

80. Pohlman R, Lehfeldt E (1966) Influence of ultrasonic vibration on metallic friction. Ultrasonics 4:178-185

81. Lucas M (1996) Vibration sensitivity in the design of ultrasonic forming dies. Ultrasonics 34(1):35-41

82. Maeno T, Osakada K, Mori K (2011) Reduction of friction in compression of plates by load pulsation. Int J Mach Tool Manu 51:612-617

83. Maeno T, Mori K, Hori A (2014) Application of load pulsation using servo press to plate forging of stainless steel parts. J Mater Process Technol 214:1379-1387

84. Maeno T, Mori K, Ichikawa Y, Sugawara M (2017) Use of liquid lubricant for backward extrusion of cup with internal splines using pulsating motion. J Mater Process Technol 244:273-281

85. Dean TA, Shergold MD (1990) University/industry collaboration leads to precision forge production facility. Metallurgia 57(8):322324 